\title{
PEER REVIEW REPORT
}

for

Revision 1 of DOE/RW-0184,

"Characteristics of Potential Repository Wastes"

Date Published: October 1992

Prepared for the

U.S. Department of Energy

Office of Civilian Radioactive Waste Management

(Activity No. DB 0402 11)
Prepared by
C. G. Cowart
K. J. Notz

Oak Ridge National Laboratory

Oak Ridge, Tennessee 37831-6495

managed by

Martin Marietta Energy Systems, Inc.

for the

U.S. Department of Energy

under contract DE-AC04-84OR21400

Accepted by

W. A. Lemeshewsky, Chief

Systems Engineering Branch

Office of Civilian Radioactive Waste Management

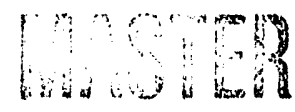




\section{CONTENTS}

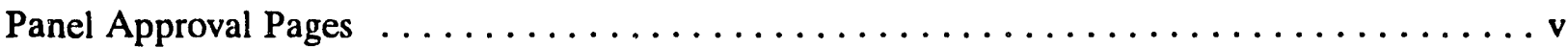

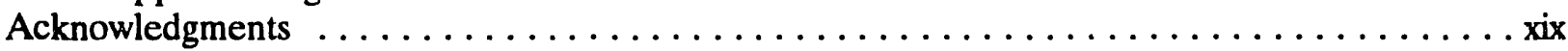

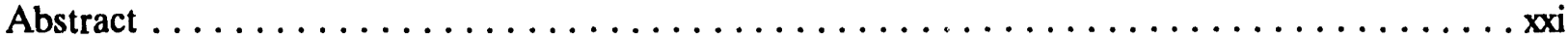

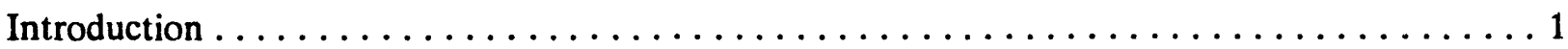

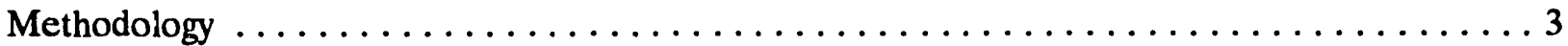

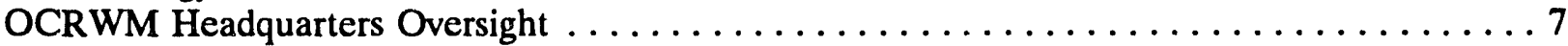

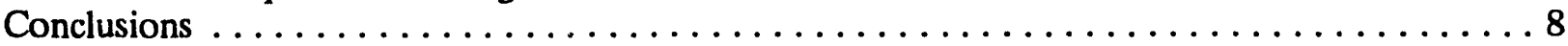

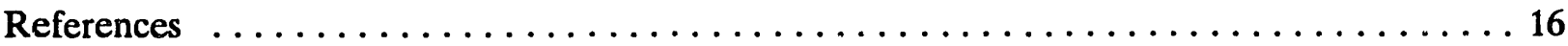

Appendices:
A Peer Review Plan
B Chronological Summary of Significant Peer Review Process Events
C Quality Assurance Records Categories
D Recommendations for Future Characteristics Data Base (CDB) Editions
E Lessons Learned for Future OCRWM Peer Reviews
F Qualifications of Peer Reviewers

Distribution 
for the

\section{Summary and Overall Panel}

Original signed by R.G. Eble *

Robert G. Eble

Duke Engineering and Services, Inc.

Original signed by D.J. Harrison-Giesler *

Diane J. Harrison-Giesler

U.S. Department of Energy, Yucca Mountain Project

Original signed by C.L. Kerrigan *

Camille L. Kerrigan

TRW Environmental Safety Systems

Original signed by I.J. Sacks *

Ivan J. Sacks

R\&D Associates

Original signed by H.A. Worle *

Helmut A. Worle

EG\&G Idaho
29 September 1992

Date

30 May 1992

Date

22 May 1992

Date

11 June 1992

Date

15 May 1992

Date

* Original signature page is in the CDB Peer Review QA Records file.

Certified:
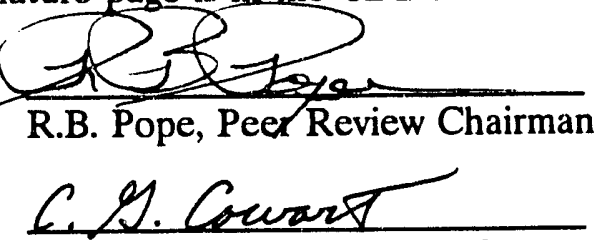

C.G. Cowart, Peer Review Secretary

(Approval of this report indicates that the peer reviewer is satisfied that the information contained in DOE/RW-0184, Rev. 1, is quality determined and suitable for use in quality-affecting work) 
APPROVAL PAGE

for the

\section{LWR Spent Fuel Panel}

Original signed by B.M. Cole *

Billy M. Cole

E.R. Johnson Associates, Inc.

Original signed by R.W. Lambert *

Ray W. Lambert

Electric Power Research Institute

Original signed by H.R. Leider *

Herman R. Leider

Lawrence Livermore National Laboratory

Original signed by A.T. Luksic *

Andy T. Luksic

Pacific Northwest Laboratory

Original signed by J.E. Mendel *

John E. Mendel

Pacific Northwest Laboratory
14 July 1992

Date

26 May 1992

Date

18 May 1992

Date

08 July 1992

Date

15 May 1992

Date

* Original signature page is in the CDB Peer Review QA Records file.

Certified:
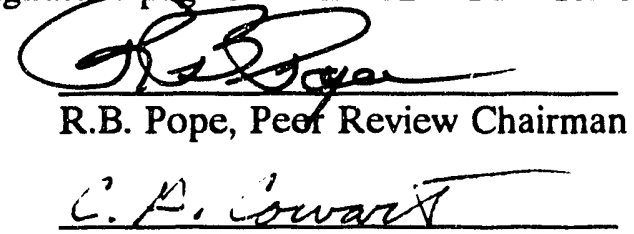

C.G. Cowart, Peer Review Secretary

(Approval of this report indicates that the peer reviewer is satisfied that the information contained in DOE/RW-0184, Rev. 1, is quality determined and suitable for use in quality-affecting work)

vii 
APPROVAL PAGE

for the

\section{Non-Fuel Assembly Hardware Panel}

Original signed by A.T. Luksic*

Andy T. Luksic

Pacific Northwest Laboratory

Original signed by J.L. Wheeler *

James L. Wheeler

Private Consultant

Original signed by M.J. White *

Michael J. White

E.R. Johnson Associates, Inc.
21 August 1992

Date

15 July 1992

Date

31 July 1992

Date

* Original signature page is in the CDB Peer Review QA Records file.

Certified:
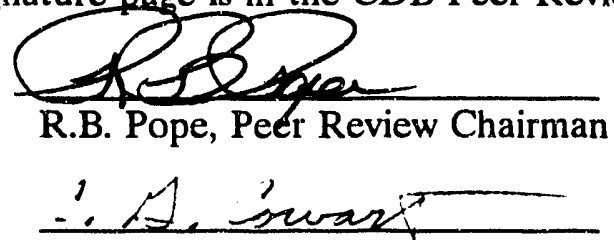

C.G. Cowart, Peer Review Secretary

(Approval of this report indicates that the peer reviewer is satisfied that the information contained in DOE/RW-0184, Rev. 1, is quality determined and suitable for use in quality-affecting work.) 
APPROVAL PAGE

for the

\section{High Level Waste Panel}

Original signed by F.M. Coony*

F. Michael Coony

Westinghouse Hanford Company

Original signed by H.W. Godbee *

Herschel W. Godbee

Martin Marietta Energy Systems, Inc.

Original signed by C.L. Bendixsen *

C. Lee Bendixsen

Westinghouse Idaho Nuclear Company

Original signed by R.A. Palmer *

Ronald A. Palmer

West Valley Nuclear Services Company

Original signed by M.J Plodinec *

M. John Plodinec

Westinghouse Savannah River Company

Original signed by R.A. Watrous *

Robert A. Watrous

Westinghouse Hanford Company

* Original signature page is in the CDB Peer Review QA Records file.

Certified:
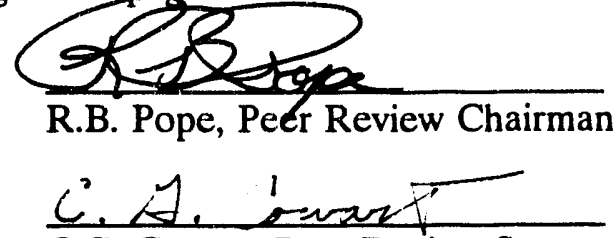

C.G. Cowart, Peer Review Secretary
08 September 1992

Date

22 July 1992

Date

26 May 1992

Date

12 May 1992

Date

12 May 1992

Date

10 September 1992

Date

(Approval of this report indicates that the peer reviewer is satisfied that the information contained in DOE/RW-0184, Rev. 1, is quality determined and suitable for use in quality-affecting work) 
for the

\section{Non-LWR Spent Fuel Panel}

Original signed by N.D. Rickard *

N. Douglas Rickard

General Atomics

Original signed by C.L. Bendixsen *

C. Lee Bendixsen

Westinghouse Idaho Nuclear Company

Original signed by M.J. Beckum *

Matthew J. Beckum

Westinghouse Savannah River Company

Original signed by R.L. Pearson *

Ray L. Pearson

Martin Marietta Energy Systems, Inc.
06 July 1992

Date

26 May 1992

Date

27 May 1992

Date

27 July 1992

* Original signature pagg is in the CDB Peer Review QA Records file.

Certified:

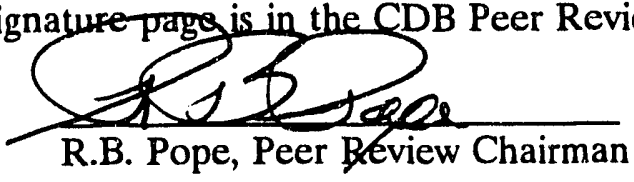

L' $y$. jesar $\mathbb{X}$

C.G. Cowart, Peer Review Secretary

(Approval of this report indicates that the peer reviewer is satisfied that the information contained in DOE/RW-0184, Rev. 1, is quality determined and suitable for use in quality-affecting work.) 
for the

\section{Miscellaneous Wastes Panel}

Original signed by M. Rahimi *

Meraj Rahimi

Jacobs Engineering Group, Inc.

Original signed by M.T. Magleby *

Mary T. Magleby

EG\&G Idaho

Original signed by R.R. Piscitella *

Roger R. Piscitella

EG\&G Idaho
12 May 1992

Date

19 May 1992

Date

15 May 1992

Date

* Original signature page is in the CDB Peer Review QA Records file.

Certified:

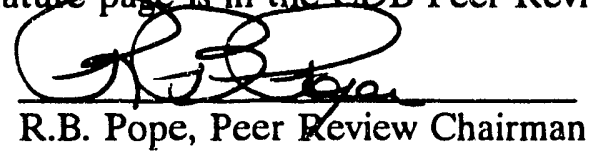

$\frac{\text { C. S. Covare }}{\text { C.G. Cowart, Peer Review Secretary }}$

(Approval of this report indicates that the peer reviewer is satisfied that the information contained in DOE/RW-0184, Rev. 1, is quality determined and suitable for use in quality-affecting work.) 
for the

\section{ORIGEN2 Panel}

Original signed by $D$. Andress *

David Andress

David Andress and Associates, Inc.

Original signed by N.B. McLeod *

N. Barrie McLeod

E.R. Johnson Associates, Inc.

Original signed by M.L. Smith *

Marvin L. Smith

Virginia Power/Private Consultant
14 August 1992

Date

03 August 1992

Date

15 July 1992

Date

* Original signature page-ing the

Certified:

R.B. Pope, Peof Review Chairman

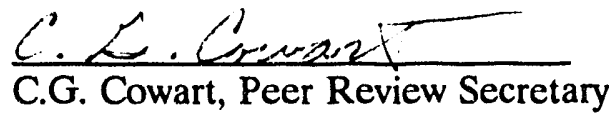

(Approval of this report indicates that the peer reviewer is satisfied that the information contained in DOE/RW-0184, Rev. 1, is quality determined and suitable for use in quality-affceting work)

xvii 


\section{ACKNOWLEDGMENTS}

The peer review documented in this report was successfully conducted for the Systems Engineering Branch of the Office of Civilian Radioactive Waste Management through the conscientious efforts of the peer reviewers for each panel who approved this report. Also, recognition is due the following individuals for their efforts in resolving the reviewer's comments and ensuring that all accepted comments were correctly incorporated into DOE/RW-0184, Rev. 1, or the six PC data bases which supplement that document.

Royes Salmon (Martin Marietta Energy Systems, Inc.)

Tim D. Welch (Martin Marietta Energy Systems, Inc.)

Willaim J. Reich (Martin Marietta Energy Systems, Inc.)

R. Scott Moore (Automated Sciences Group, Inc.)

Elizabeth A. Dorsey (Automated Sciences Group, Inc.)

Kathy Jones (Dataphile) 


\begin{abstract}
This report presents the results of a fully documented peer review of DOE/RW-0184, Rev. 1, "Characteristics of Potential Repository Wastes". The peer review was chaired and administered by Oak Ridge National Laboratory (ORNL) for the Department of Energy (DOE), Office of Civilian Radioactive Waste Management (OCRWM) and was conducted in accordance with OCRWM QA procedure QAAP 3.3 "Peer Review" for the purpose of qualifying the document for use in OCRWM quality-affecting work. The peer reviewers selected represent a wide range of experience and knowledge particularly suitable for evaluating the subject matter. A total of 596 formal comments were documented by the seven peer review panels, and all were successfully resolved. The peers reached the conclusion that DOE/RW-0184, Rev. 1, is quality determined and suitable for use in quality-affecting work.
\end{abstract}




\section{INTRODUCTION}

This report documents the results of the peer review of DOE/RW-0184, Rev. $1^{1}$, a 4-volume document plus six PC data bases, which was determined by the Office of Civilian Radioactive Waste Management (OCRWM) to be "quality-affecting" because it will be used as an input source into the design of components of the Civilian Radioactive Waste Management System (CRWMS) - formerly the Federal Waste Management System (FWMS). The "quality-affecting" designation requires that the document must be developed under an OCRWM approved Quality Assurance (QA) Program.

The original version of DOE/RW-0184, which was titled "Characteristics of Spent Fuel, High-Level Waste, and Other Radioactive Wastes which may Require Long-Term Isolation," was issued in eight volumes, six in December 1987 and the rensaining two in June 1988. ${ }^{2}$ These eight volumes were supported by five menu-driven PC data bases. Much of the data in the printed report was taken directly from these PC data bases. Rev. 1 was based on Rev. 0 and consequently had the benefit of field review by the many users of Rev. 0 .

The decision to conduct a fully documentsd neer review occured as a result of an OCRWM-HQ QA Surveillance ${ }^{3}$ conducted March $20-23,1990$. During that surveillance it was determined that the document had not been developed under an OCRWM-approved QA program (although efforts had been underway at ORNL to develop a QA program acceptable to HQ, both Rev. 0 and Rev. 1 were developed before that occurred). That conclusion was documented in a Deficiency Report ${ }^{4}$ which required OCRWM management to take remedial action. Since DOE/RW-0184 was an existing document, peer review was selected as the best of the options available to qualify the document for use in "quality-affecting" work. Subsequently, Oak Ridge National Laboratory (ORNL) - the document developer - was directed in the DOE FY 1991 Funding and Guidance memorandum (dated December 21, 1990) to undertake a formal peer review of Rev. 1, which was then in draft.

Rev. 1 of DOE/RW-0184 was issued in draft form for the peer review in six volumes. The peer review has been completed and the results are documented herein. After acceptance of this peer review report by OCRWM, including incorporation of accepted comments, Rev. 1 of DOE/KW-0184 will be issued to a controlled distribution in four volumes - the six volumes originally scheduled to represent the $\mathrm{CDB}$ for the peer review were compressed into four during the review process. The purpose of the peer review was to qualify Rev. 1, under the applicable portions of the OCRWM QA program, and to complete the remedial action required to support closure of the Deficiency Report corrective actions. Portions of the OCRWM QA program applicable to the peer review include Quality Assurance Administrative Procedures (QAAPs) 2.1, 2.2, 3.1 and 3.3, as appropriate, and Nuclear Regulatory Commission documents NUREG-1297 and NUREG-1298. ${ }^{5,6,7,8,9,10}$

Rev. 1 includes the five original PC data bases (which have also been revised) plus an additional data base, for a total of six. The general structure and content of the 6 volumes and the 6 PC data bases of Rev. 1 are outlined in the Peer Review Plan (Appendix A). Collectively, these are referred to as the Waste Characteristics Data Base or simply the Characteristics Data Base (CDB). Rev. 1 includes updating, revision, and expansion of the original data base. The more significant changes are also described in the Peer Review Plan. 
The format of the printed volumes has been revised somewhat by the incorporation of two volumes of appendices into other volumes and elimination of the PC data base User's Guides. The scope of coverage remains as it was in the original version: LWR Spent Fuel, High-Level Waste, Non-LWR Spent Fuel, and Miscellaneous Wastes.

The objectives in having prepared the CDB were (a) to provide OCRWM with a single, unified source of detailed technical data on potential repository wastes, and (b) to make this information available to all parts of OCRWM and OCRWM contractors involved in planning and implementing the CRWMS. This includes systems integration/engineering, storage, transportation, and disposal. The kinds of technical data tabulated in the CDB are outlined in Table 3 of the Peer Review Plan (Appendix A).

The CDB relies on the EIA (Energy Information Administration) for basic LWR spent fuel data and utilizes the ORIGEN2 computer code to calculate radiological properties. This peer review qualified specific usage of EIA data and ORIGEN2 calculations in Rev. 1; it does not provide generic qualification for either EIA data or the ORIGEN2 computer code. Generic QA qualification for EIA data and the ORIGEN2 computer code will only be possible when those programs implement their own OCRWM approved QA programs.

Four other appendices are included with this report as follows: Appendix B is a chronological listing of significant events in the peer review process, Appendix $C$ identifies the categories of supporting QA documentation, Appendix D presents recommendations for future areas of study and enhancements to the data base system, and Appendix E enumerates lessons learned during the peer review.

Although it did not change the peer review process, the award of a Management and Operating (M\&O) contract by OCRWM early in 1991 is noted here because it is significant to the future of the $\mathrm{CDB}$ and resulted in the inclusion of $\mathrm{M} \& \mathrm{O}$ representatives on the Summary and Overall panel. 


\section{METHODOLOGY}

The peer review process began with preparation of the Peer Review Plan, SI-PR-001 (Appendix A), which met the requirements of QAAP 3.3, Rev. 0, "Peer Review". The following topics were required to be addressed in the Plan:

- Organization of the peer review group, including a chairman, secretary, and technicallyqualified peer review panels;

- Identification of specialized technical areas and structure of the peer review panels;

- Duties and qualifications of the peer review group chairman, secretary, and panel members;

- Review criteria and methodology;

- Submittal of comments and response;

- Comment resolution meeting;

- Preparation of the peer review final report; and

- Schedule to be followed.

The peer review group was formed and consisted of a chairman, secretary, and peer reviewers, whose qualifications and duties were described in the Peer Review Plan. Because of its technical scope, peer review of DOE/RW-0184, Rev. 1, required seven review panels, each consisting of three or more members. A chronological summary of significant events in the peer review process is provided as Appendix B.

The OCRWM Systems Integration Program Manager at ORNL was designated by OCRWM management as the peer review chairman. The peer review chairman was also delegated responsibility, under section 4.0 of QAAP 3.3, to appoint members to the peer review panels, determine the scope of the peer review, establish peer reviewer qualifications, and assure that the peer review plan was prepared and carried out. This delegation of responsibility was documented on the approval sheet of the Peer Review Plan.

The technical areas and structure of the peer review panels were described in the Peer Review Plan. In order to achieve the goal of determining technical competence and organizational comprehensiveness, the panel members were selected to represent a spectrum of Department of Energy (DOE), contractor, and utility interests. Substitutions or additions of panel members were made at the discretion of the peer review group chairman, with confirmation by the responsible OCRWM Program Manager. The duties and qualifications of the chairman, secretary and peer reviewers were described in the Peer Review Plan; all were documented and verified prior to participation in the peer review process. A summary of the technical qualifications of each peer reviewer is provided in Appendix F. Full documentation of peer reviewer technical qualifications and evidence of independence is not included with this report because of the volume of information required to document 29 peer reviewer positions, but is instead preserved in the QA records package as indicated in Appendix $\mathrm{C}$.

DOE/RW-0184, Rev. 1, was reviewed by the peer review panel members for its adequacy, in terms of accuracy, assumptions, calculations, extrapolations, interpretations, methodology, and references. In this instance, since the CDB document is simply a data base, there were no conclusions as such to be critiqued. Because of the nature of DOE/RW-0184, documentation of data sources was an especially important aspect of the peer review. Reviewers were instructed to pay particular attention 
to the following:

Adequacy: Is enough information provided? Is it provided in a suitable format? Where explanations are needed, are they given?

Accuracy: Are the data and other information correct? Are they presented correctly?

References: Are the proper references provided? Are enough references provided? Have the references been cited correctly?

In addition, the following factors were also highlighted for consideration by the reviewers:

- Validity of basic assumptions and acceptance requirements employed;

- Uncertainty of results, and consequences if incorrect;

- Appropriateness and limitations of methodology and procedures;

- Alternative interpretations; and

- Verification of computer software.

The procedures used were as follows: Each reviewer reviewed those portions of the subject matter delineated in Table 5 (Responsibilities of Each Panel) of the Peer Review Plan and as specifically instructed in each reviewer's copy of the Peer Review transmittal letter. The reviewers used the comment form shown in Table 10 of the Peer Review Plan to document each comment. The comment form provided a uniform format which identified the location in the text, gave the comment, provided space for the author's response, and provided a place for the reviewer's final resolution. Reviewers were also allowed to mark up the item in question on the draft report and submit a copy of the applicable page with the comment form.

Reviewers were instructed to submit comments one per page (wherever it was not unreasonable to do so). This facilitated all steps of the review process. Generic comments, applicable to more than one specific location, were allowed to be made using the standard form, citing the multiple locations to which the same comment applied. Reviewers were also instructed to use corroborating data or results of confirmatory testing (if acquired under a 10 CFR 60, subpart G QA program) for the purpose of establishing the qualification of the material subject to the peer review, should those techniques be appropriate. Minor editorial comments (spelling, obvious typos, etc.) were not an objective of the peer review but were welcomed. Reviewers were requested to simply list those on a single piece (or pieces) of paper, or mark them directly on the reviewer's copy of the document and return them to the chairman.

The chairman was tasked with arranging for copies of references or other documents, requested by individual reviewers, to be transmitted to those reviewers on an as-needed basis. The chairman was also required to assure that the materials transmitted were the correct revisions, editions, etc. In late May 1991, the review process was upset by the death of the original chairman. This unfortunate event caused delays and restructuring before the process was put back on track with the appointment of a new chairman. 
As comment forms were submitted to the chairman by the peer reviewers, they were turned over to the peer review secretary for processing. Each comment form was assigned a unique number to help assure proper identification, continuity throughout the process, and reduction of the risk of confusion and error. The comment forms were logged in by the secretary and copies were immediately delivered to the authors for development of responses. Any attachments to comment forms were identified with the same comment form number. Through all steps of the process, the original comment forms were maintained in a locked file cabinet. The forms were only removed to allow the authors responses to be typed onto the originals, or to transmit the forms back to the reviewer for resolution.

After responses were completed by the authors, each peer reviewer's comment forms were logged by the secretary and returned to the reviewer for resolution. Where resolution was successfully accomplished, the reviewer formally accepted and signed each comment form and the original forms were indexed and retained as completed QA records. Copies of completed comment forms and any accompanying material were also given to the authors for updating DOE/RW-0184, Rev. 1, to its final form for publication.

Where resolution by the authors was not completely successful, one of two outcomes could result:

1) The reviewer could accept the resolution with conditions which appear in the "CONCLUSIONS" section of this report as a dissenting opinion or alternative interpretation, or

2) The reviewer could reject the resolution, the authors were unable to further resolve the rejection, and a comment resolution meeting was conducted.

a) Where a resolution meeting successfully resolved an impasse, the comments in dispute were accepted by the reviewer.

b) Where a resolution meeting was unsuccessful at resolving an impasse, the comments in dispute were dispositioned by the peer review chairman and the reviewer's dissenting opinion appears in the "CONCLUSIONS" section of this report.

Outcome 2a) did occur during the peer review process; however, neither outcome 1) nor 2b) occurred since none of the reviewers chose to express a dissenting opinion in this report either as a result of individual negotiation efforts or a panel meeting. Reviewer's concerns are documented in the CONCLUSIONS section of this report while others are more appropriately included in the RECOMMENDATIONS section (Appendix D) to indicate that the concern should be considered in future $\mathrm{CDB}$ work.

One type of deviation worth noting occurred twice in that two reviewer's wrote their comments in pencil rather than ink on the comment forms. This situation was remedied by photocopying those comment forms and then identifying the copies as "first generation xerox of original paper copies". The copies then became the master documents, were used for the response and resolution process, and became QA records. The forms prepared in pencil were also retained and will be turned over to the OCRWM Program Manager as part of the peer review QA records package. Another exception worth noting occurred when a set of original comments was lost between the response and resolution phase. The backup set of comment forms was pulled from the records file and each form 
was identified as a "first generation copy of original comment form". This set of forms was then designated as the new original copy set and used to complete the resolution phase.

After all comments were resolved, this peer review report was prepared and approved by each peer reviewer. The CDB authors updated DOE/RW-0184, Rev. 1, in accordance with the complete peer review comment set and the revised documents were sent to each reviewer for their acceptance of comment incorporation. In addition, incorporation of accepted comments was given 100 percent verification at ORNL by the peer review secretary.

After acceptance of the Peer Review report by OCRWM, all peer review records will be turned over to the OCRWM Office of Systems and Compliance (OSC) Program Manager for disposition into the OCRWM QA records system. A listing of QA records categories is provided as Appendix $C$ to this report. 


\section{OCRWM HEADQUARTERS OVERSIGHT}

During the course of the peer review, two independent assessments of the process were conducted by OCRWM Headquarters. Both assessments proved to be an asset by validating the review process and bv evaluating the effectiveness of the review. Summaries of the two activities are given below and details are available in the respective reports which are included in the records package to be delivered to OCRWM at the conclusion of the process.

\section{OCRWM Surveillance of the Peer Review Process}

On March 19, 1991 the peer review chairman requested that the OSC technical contact arrange for the OCRWM Office of Quality Assurance (OQA) to conduct a QA surveillance of the peer review process at ORNL. The letter stated in part "Our reason for wanting to do this is to reassure ourselves and you that we have established viable and realistic approaches likely to lead to a successful conclusion in accordance with QAAP 3.3. Furthermore, a surveillance at this time would permit us to take corrective actions should any significant deficiencies be discovered before the process is too far along." The chairman intended that the surveillance should be scheduled to occur after the peer review panels had begun to transmit comments but early enough to correct any weaknesses in implementation.

Subsequently, a surveillance ${ }^{2}$ was conducted on July $18-19,1991$ by OQA representatives and was observed by the OSC technical contact. The surveillance report summarized that peer review activities were being effectively implemented. No Corrective Action Requests (CARs) resulted from the review; however, four minor discrepancies were observed in the surveillance report - these were subsequently corrected.

\section{OCRWM Audit of the Systems Integration Program}

OCRWM Headquarters scheduled and conducted an audit ${ }^{11}$ of the Systems Integration Programs "quality-affecting" activities to assess implementation of the QA program. The audit scope included the peer review process. One of the three audit findings affected the peer review process and the deficiencies identified were documented by OQA in a Corrective Action Request ${ }^{12}$ which described the following weaknesses in several of the peer reviewer packages sampled: a) not enough documentation to substantiate qualifications, b) incomplete Certification of Independence forms, and c) lack of documentation of panel member substitution.

Item c) was corrected prior to close-out of the audit. Items a) and b) were subsequently corrected through requests for additional information from the affected peer reviewers. 


\section{CONCLUSIONS}

The conclusions presented for each panel include a composite summary of that panel's assessment, statements by individual reviewers selected for their significance to the material reviewed, and any dissenting opinions provided by specific reviewers. All reviewer comment forms are included in the QA records package to be delivered to OCRWM at the conclusion of the peer review process should there be an interest by a reader of this report in obtaining additional detail as to the panel members' observations, recommendations or interpretations concerning any of the material reviewed. Appendix $\mathrm{D}$ to this report delineates specific recommendations by reviewers for future work on the CDB document and PC databases. Throughout the conclusions section of this report, the unique number assigned to each comment form cited is given in parentheses next to each statement quoted or paraphrased to provide a cross reference to the exact location of the statement made by a panel member. Also, citations are given parenthetically to a panel member's correspondence where appropriate. Such correspondence is also found in the QA records package to be delivered to OCRWM at the conclusion of the peer review process.

\section{Summary and Overall Panel}

\section{- Summarization of Results:}

No controversial opinions resulted from this review by the five panel members, nor anything which could be considered highly critical of the overall CDB data or its presentation. A total of 54 comments were documented and all were resolved during the process; therefore, a panel meeting was not needed. Comments typically concerned such things as editorial corrections, clarification of phrasing in the text, including additional data tables and improving existing column headings, level of detail on data sources, and correcting a cause of similar programming errors in the Serial Number Data Base.

\section{- Individual Statements of Significance:}

C.L. Kerrigan (letter dated 07/11/91) made a positive observation that "The CDB is an excellent system, providing data that would be difficult for most users to obtain easily. I believe this system is providing a real service to the OCRWM community." Conversely, in the same letter she noted in regard to verification of computer software that "There is little information in the report or in the PC version of the data base on computer software used to generate the $\mathrm{CDB}$ reports (both hard copy and electronic) or computer software which transiers data from source to CDB files. Therefore, it was not possible to consider verification of this software." This statement has significant implications for the future management of the CDB and is also addressed in the recommendations section (Appendix D) of this report.

I.J. Sacks favorably noted (letter dated 07/19/91) that "In general, I feel that the PC-based CDB is very good and a major and useful product." 
D.J. Harrison-Giesler (DHG-001) addressed an issue which does not impact the quality of the data in Rev. 1 of the CDB but which does have significant potential impact on the CRWMS. "The report does not deal with the issue of reactor life extension. This will slow the decrease in total nuclear capacity after the year 2000, will increase the quantities of spent fuel discharged annually (compared to the current base case), and will increase the cumulative quantities of fuel for disposal."

- Dissenting Opinions: None of the panel members found it necessary to express a dissenting opinion on the CDB. All comments made by this panel were resolved.

\section{LWR Spent Fuel Panel}

\section{- Summarization of Results:}

In general, this review by the five panel members resulted in no major problems and all comments were resolved during the process; therefore, a panel meeting was not needed. Of the 107 comments generated, only three will be specifically elaborated upon here. The other comments dealt mostly with suggestions for and improvements to the PC data base system, textual phrasing and clarifications, editorial corrections, references to data sources, and occasional numerical errors.

One area of controversy, with potential for significant impact, concerned the inclusion of LWR quantities data in the CDB. This issue was raised by B.M. Cole in his letter of April 18,1991 , continued on comment forms (BMC-006 and BMC-030), and finally brought to conclusion after several telephone calls and written exchanges with the senior $\mathrm{CDB}$ author. Resolution was obtained when text was added to the CDB Volume 1 in both the Foreword and paragraph 2.3.1, which more fully and emphatically identifies the Energy Information Administration (EIA) as the official source of the quantities data, and which alerts the users of the $\mathrm{CDB}$ to the temporal limitations on the data presented in the document.

An area of concern expressed by A.T. Luksic in his comments (ATL-010) was the use of a new cross-section library in ORIGEN2 computer code runs which are in turn used as the basis for the entire LWR Spent Fuel data base, and that these cross-sections had not been made available for review. This issue was satisfactorily resolved after transmittal of the new cross-sections to Mr. Luksic; these cross sections are now also available to the general public.

\section{- Individual Statements of Significance:}

B.M. Cole stated (letter dated 04/18/91) that "The PC data bases were exercized and found to be as advertised -- i.e., self tutorial and very easy to follow."

R.W. Lambert stated (letter dated 04/26/91) that "Overall, I find the document very well formulated and to be of high quality." 
H.R. Leider stated (letter dated 04/08/91) that "As you will see, I have no real problems with the document. Referring to Section 6 of the Peer Review Plan, Review Criteria, I believe that Adequacy and Accuracy are satisfied; with the exceptions noted, References are proper and adequate. The other factors listed are also met, in my view."

J.E. Mendel stated (letter dated 04/18/91) that "Generally, I found the report of high quality. It and the PC data bases should be very useful to the FWMS."

- Dissenting Opinions: None of the panel members found it necessary to express a dissenting opinion on the CDB. All comments made by this panel were resolved.

\section{Non-Fuel Assembly Hardware Panel}

\section{- Summarization of Results:}

In general, this review by the three panel members resulted in no major problems and all comments were resolved during the process; therefore, a panel meeting was not needed. Of the 35 comments generated, only one will be specifically elaborated upon here. The other comments dealt mostly with enhancements to and clarification of the text, editorial corrections, definition of terms used, additional discussion of data presented, corrections to reactor identification and status, and discussion of methods used to characterize radiological properties.

J.L. Wheeler's comment (JLW-010) concerning the ORIGEN2 radionuclide inventories for materials irradiated in core proved difficult to resolve in that it hinged on providing ORIGEN2 outputs for materials which are not currently available. Agreement was reached between Mr. Wheeler and the CDB authors by a change to the text which acknowledged that calculated inventories for other irradiated materials are scheduled for development and will be published separately.

- Individual Statements of Significance:

No statements which could be characterized as significant, beyond the ORIGEN2 inventories for other materials issue discussed above, were identified in either the correspondence or comments of this panel.

- Dissenting Opinions: None of the panel members found it necessary to express a dissenting opinion on the CDB. All comments made by this panel were resolved. 


\section{High Level Waste Panel}

\section{- Summarization of Results:}

No controversial opinions resulted $f(s m$ this review by the six panel members, nor anything which could be considered highly critical of the High Level Waste data or its presentation. A total of 122 comments were documented and all were resolved during the process; therefore, a panel meeting was not needed. Comments typically concerned such things as editorial corrections, clarification of the units of numbers, replacing or updating references to data sources, format of data tables and occasional numerical errors. For example, more than half $(62 \%)$ of the panel's comments came from H.W. Godbee, and these were mainly directed at phrasing in the text, format of the data tables, and references to data sources.

\section{- Individual Statements of Significance:}

M.J. Plodinec favorably commented on the HLW Data Base System (MJP-019) as follows: "In general, this is an excellent scheme, well-implemented."

R.A. Watrous expressed a concern (letter dated 09/11/91) as follows: "During this latest review, we have become more concerned than before over the 'canister count' disparity between your data (based on the TURNER 1990 reference) and our more recent canister projections. We recognize your need to freeze the data base for your report; however, the tendency of the reader will be to assume that your report represents the latest 1991 projections." This concern was addressed by adding text to paragraphs 1.3.1, 3.1.2 and 3.1.4 of CDB Volume 1 which now alerts the reader to potential data base updates.

- Dissenting Opinions: None of the panel members found it necessary to express a dissenting opinion on the CDB. All comments made by this panel were resolved.

\section{Non-LWR Spent Fuel Panel}

\section{- Summarization of Results:}

No controversial opinions resulted from this review by the four panel members, nor anything which could be considered highly critical of the Non-LWR Spent Fuel data or its presentation. A total of 148 comments were documented and all were resolved during the process; therefore, a panel meeting was not needed. Comments typically concerned such things as editorial corrections, clarification of phrasing in the text, replacing or updating references to data sources, including additional data tables, updating specifications and correcting occasional numerical errors. For example, more than half $(78 \%)$ of the panel's comments came from R.M. Pearson which were largely directed at phrasing in the text; data table column headers; selection of facilities reported; dimensions, quantities and enrichment percentages reported; decommissioning dates; and references to data sources. 
- Individual Statements of Significance:

C.L. Bendixsen (letter dated 09/05/91) stated "I have reviewed the requested portions of the DOE/RE-0184-R1 draft document, relative to non-LWR fuels stored at the INEL. The data and decriptive wording therein have been compared with earlier documents and data supplied to ORNL. No comments appear to be needed at this time."

M.J. Beckum (MJB-002, MJB-003, MJB-004, MJB-005 and MJB-006) repeatedly raised the issue of the difference between the inventory (quantities) reported in the $\mathrm{CDB}$ and the current Savannah River Site numbers which is significant in that it emphasizes the need for users to be aware that the $\mathrm{CDB}$ must (by nature) be frozen at the point of publication.

- Dissenting Opinions: None of the panel members found it necessary to express a dissenting opinion on the CDB. All comments made by this panel were resolved.

\section{Miscellaneous Wastes Panel}

- Summarization of Results:

No controversial opinions resulted from this review by the three panel members, nor anything which could be considered highly critical of the Miscellaneous Wastes data or its presentation. The comments focused consistently on two areas. First, was the incorpor ation of data found in DOE/LLW-114 ${ }^{13}$ (which was issued after the draft of DOE/RW-0184, Rev. 1, was released). Reviewers M.T. Magleby and R.R. Piscitella repeatedly emphasized the need to use this current data in the CDB. Second, was the need to clearly distinguish between GTCC and TRU wastes. The reviewers pointed out that clarifying these terms throughout could avoid confusion in the definition of GTCC LLW.

A total of 78 comments were documented and all were resolved during the process; therefore, a panel meeting was not needed. Other comments, in addition to the issues raised above, typically concerned such things as editorial corrections, clarification of phrasing in the text, usage and harmonization of terms, replacing or updating references to data sources, including additional data tables, updating specifications, clarifying calculation methods, and correcting occasional numerical errors. For example, more than half $(55 \%)$ of the panel's comments came from M.T. Magleby which were largely directed at phrasing in the text, classification of $u$ astes, disposal of waste types, organization of the material and references to data sources.

\section{- Individual Statements of Significance:}

M.T. Magleby (MTM-005) introduced DOE/LLW-114 by stating "This list of typical examples of GTCC LLW should be updated to correspond to the new informantion available in DOE/LLW-114, Greater-Than-Class C Low-Lezel Radioactive Waste Characterization: Estimated Volumes, Radionuclide Activities and Other Characteristics." Reference to this document recurred in many subsequent comments by both Magleby and Piscitella concerning other aspects of this $\mathrm{CDB}$ chapter. 
R.R. Piscitella (RRP-001) stated "It is very important in discussions of these wastes to clearly distinguish between GTCC LLW and DOE owned TRU waste. GTCC LLW, by law (LLRWPAA), is required to be disposed of by DOE in a NRC licensed facility while TRU waste is not. This distinction affects how the waste is handled, stored, and disposed of. The Introduction should clearly establish this distinction and it should be carried through out the whole chapter."

M. Rahimi (MR-012) stated "It is not clear if the specific activities for the radionuclides have been calculated based on burial volume, minimum volume, or theoritical volume. This is important because it determines which activiated components would be greater than class $\mathrm{C}$ waste. For conservatism, the theoretical volume should be used in determination of specific activities of the radionuclides if not already used."

- Dissenting Opinions: None of the panel members found it necessary to express a dissenting opinion on the CDB. All comments made by this panel were resolved.

\section{ORIGEN2 Panel}

- Summarization of Results:

This panel generated more controversial issues than any of the other panels, as indicated in the numerous recommendations found in Appendix D of this report. ORIGEN2 was the only panel which required the chairman to convene a meeting to resolve comments which could not be finalized with the individual peer reviewers. The panel meeting was conducted at ORNL on July 24, 1991; the minutes of that meeting are documented in a memorandum from the Peer Review Secretary to the Chairman dated July 29, 1991 (QA records file) which also includes the attendence sheet (two observers from TRW Environmental Safety Systems as well as the CDB Task Manager and staff were in attendance). Unresolved comments of reviewers D. Andress, N.B. McLeod and M.L. Smith were addressed at that meeting (Smith could not attend). Out of the 52 total comments generated by the reviewers, the discussion centered on three basic issues as follows:

- The development of data using the ORIGEN2 computer code and its interpretation into the CDB was an area of considerable discussion. Although the ORIGEN2 code was not a subject of the peer review (as clearly stated in Section 1 of the Peer Review Plan), the impact of calculations made through its use and their manipulation for presentation in the CDB was a significant issue as detailed in comments DA-001, DA012, DA-013, DA-014, NBM-005 and NBM-006. Discontinuities were noted between the calculations for BWR and PWR for thermal power versus burnup and for neutrons. The use of interpolation functions in the CDB system computer programs, and Enrichment versus Burnup regression equations were thoroughly questioned and evaluated.

- A second area of concern was the incorporation and use of integral heat data in the CDB (NBM-001 and DA-013). The discussion centered on integral heat characteristics and results, calculation methods, and instructions for accessing the data. 
- The third area of concern was the categorization of spent fuel and its effect on decisions regarding handling, storage and disposal (MLS-003, MLS-004, MLS-006 and MLS-008).

After considerable discussion among the reviewers, CDB staff and observers most of the issues were resolved. At the conclusion of the meeting, all comments by Andress and McLeod were finalized. Several of Smith's comments remained unresolved at that time; however, these were successfully finalized at a later date as indicated on the comment forms.

\section{- Individual Statements of Significance:}

D. Andress stated (DA-001) that "Overall, the CDB document is a high quality piece of work and should be very useful to the OCRWM program."

N.B. McLeod stated (letter dated 04/26/91) that "Most importantly, the original 8 volumes and the Data Base have been a continuing reference for me, ever since their publication. They are well conceived and well structured for convenient usage. The update and enhancements appear to continue that tradition."

M.L. Smith stated (letter dated 04/24/91) that "The LWR Radiological Database is easy to use, user friendly, and appears to be well documented." Mr. Smith further stated in regard to the LWR Assemblies Data Base (letter dated 06/12/91) "this database provides a good overview of fuel assembly dimensions and radiological characteristics."

- Dissenting Opinions: None of the panel members found it necessary to express a dissenting opinion on the CDB. All comments made by this panel were resolved. In some cases the resolution was recognition that the request/comment was valid, but would have to await future work for completion and incorporation in a future revision (see Appendix D). 


\section{SUMMARY ASSESSMENT FOR ALL PANELS}

It is the conclusion of all seven panels, and each individual peer reviewer, that the information contained in DOE/RW-0184, Rev. 1, is quality determined and suitable for use in quality-affecting work. The approval signature of each peer reviewer, at the front of this report, signifies the reviewer's concurrence with this assessment. 


\section{REFERENCES}

1. Oak Ridge National Laboratory, "Characteristics of Potential Repository Wastes". DOE/RW0184, R1 (DRAFT); Volumes 1-4, July 1990; Volumes 5-6, to be issued.

2. U.S. Department of Energy, Characteristics of Spent Fuel, High-Level Waste, and Other Radioactive Wastes Which May Require Long-term Isolation, DOE/RW-0184, Vols. 1-6, December 1987; Vols. 7-8, June 1988.

3. OCRWM, Surveillance of the Development of Documents DOE/RW-0125, DOE/RW-0136, and DOE/RW-0184, OCRWM-HQ-SR-90-001.

4. OCRWM, Deficiency Report, DR-90-018.

5. OCRWM, Indoctrination and Training, QAAP 2.1, Rev. 1.

6. OCRWM, Verification of Personnel Qualifications, QAAP 2.2, Rev. 0.

7. OCRWM, Technical Document Review, QAAP 3.1, Rev. 0.

8. OCRWM, Peer Review, QAAP 3.3, Rev. 0.

9. U.S. Nuclear Regulatory Commission, Peer Review for High-level Nuclear Waste Repositories, NUREG-1297, February 1988.

10. U. S. Nuclear Regulatory Commission, Qualification of Existing Data for High-level Nuclear Waste Repositories, NUREG-1298, February 1988.

11. OCRWM, Audit of Systems Integration OA Program Implementation, HQ-92-02.

12. OCRWM, Corrective Action Request, CAR-HQ-006.

13. U.S. Department of Energy, Greater-Than-Class C Low-Level Radioactive Waste Characterization: Estimated Volumes, Radionuclide Activities and Other Characteristics, DOE/LLW-114. 
Appendix A

Document Number: SI-PR-001

\author{
PEER REVIEW PLAN \\ for Revision 1 of DOE/RW-0184 \\ "Characteristics of Potential Repository Wastes"
}

February 15, 1991

Prepared for the

U.S. Department of Energy

Office of Civilian Radioactive Waste Management

(Activity No. DB 0402 11)

Prepared by the

Oak Ridge National Laboratory

Oak Ridge, Tennessee 37831-6285

operated by

Martin Marietta Energy Systems, Inc.

for the

U.S. Department of Energy

under contract DE-AC04-84OR21400 
Appendix A (continued)

This Peer Review Plan approved by:

ORNL Task Manager and Senior Author of the Draft Report

(K J. Notz)

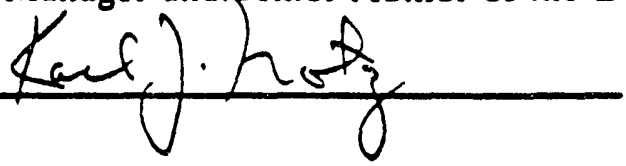

Date $2-4-91$

ORNL QA Specialist and Secretary of the Peer Review Group

(C. G. Cowart)

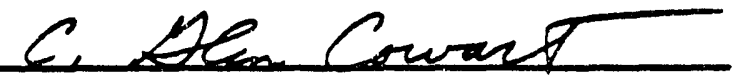

Date $22 \cdot 04-71$

ORNL Group Leader and Chairman pf the Peer Review Group

(W. c. McClain) Lilesiss C.McQla- Date 2-4-91

OCRWM Branch Chief

(W. Lemeshewsky)

Date $2 / 15 / 9 / 4$

OCRWM Division Director

(H. J. Hale)

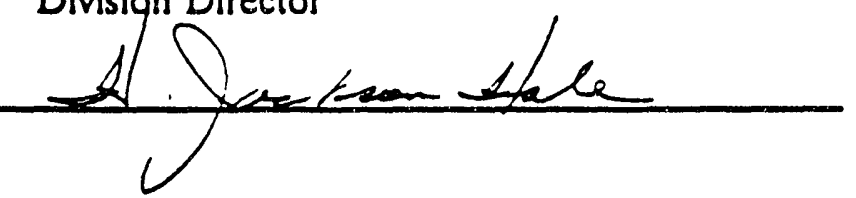

Date $2 / 15 / 41$

OCRWM Associate Director

(D. Shelor)

Associate Director

Date $2 / 15 / 8$

Designees:

The Chairman of the Peer Review Group is hereby designated to be responsible for Sections 4.1.2, 4.2.2, 4.2.3, 4.4.1, and 4.4.4 of QAAP 3.3:

OCRWM

(H. J. Hale)

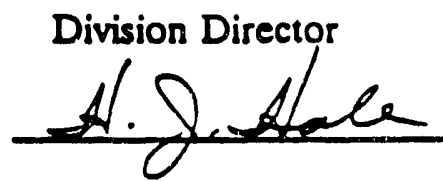

OCRWM Associate Director

(D. Shelor)

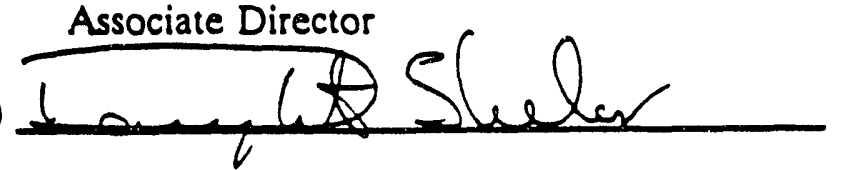

Date $2 / 15 / 91$

Date $z-20-9$ 
PEER REVIEW PLAN for DOE/RW-0184 Rev. 1, "Characteristics of Potential Repository Wastes"

\section{INTRODUCTION}

This document provides the plan for peer review of DOE/RW-0184, Rev. $1 .^{1}$ This document has been determined by OCRWM to be "quality-affecting" and will undergo a peer review because the data were not collected in conformance with an OCRWM-approved QA program. Revision 1 will be issued in draft form for peer review in six volumes. After the peer review has been completed, including incorporation of recommended changes, the six volumes will be issued for distribution. The purpose of this peer review is to qualify Revision 1 under current OCRWM QA standards. These standards include QAAPs $2.1,2.2,3.1,3.3$, as appropriate, and NUREG-1297 and-1298. ${ }^{23,4,5,6.7}$

The original version of DOE/RW-0184, which was titled "Characteristics of Spent Fuel, High-Level Waste, and Other Radioactive Wastes which may Require Long-Term Isolation," was issued in eight volumes, six in December 1987 and the remaining two in June 1988. ${ }^{8}$ These eight volumes were supported by five menu-driven PC data bases. Much of the data in the printed report was taken directly from these PC data bases. Revision 1 also includes these five PC data bases (which have also been revised) plus an additional one, for a total of six. The general structure and contents of the 6 volumes and the 6 PC data bases of Revision 1 are outlined in Tables 1 and 2. Collectively, these are referred to as the Waste Characteristics Data Base or simply the Characteristics Data Base $(\mathrm{CDB})$.

Revision 1 includes updating, revision, and expansion of the original data base. ${ }^{8}$ The more significant changes are:

An improved LWR assembly classification scheme;

More data on LWR assemblies, especially GE BWR assemblies;

Revised LWR radiological data, including specific inclusion 'enrichment, newly recalculated effective cross sections, utility data on cycle- and down-times, built-in interpolation functions for burnup, enrichment, and decay times, and an improved method for calculating integral heats;

Another PC data base, for LWR assembly serial numbers;

New activation factors for reactor hardware, based on recent experimental determinations;

The addition of fuel pin data to the assembly data base;

Improved neutron source strength data in the HLW data base; and

Improved user interface with all of the PC data bases.

The format of the printed volumes has been revised somewhat by the incorporation of two volumes of appendices into other volumes. The scope of coverage remains as it was: LWR Spent Fuel, HighLevel Waste, Non-LWR Spent Fuel, and Miscellaneous Wastes.

The objectives in having prepared the characteristics Data Base were (a) to provide OCRWM with a single, unified source of detailed technical data on potential repository wastes and (b) to make this information available to all parts of OCRWM and OCRWM contractors involved in planning and 
implementing the Federal Waste Management System. This includes systems integration/engineering, storage, transportation, and disposal. The kinds of technical data tabulated in the CDB are outlined in Table 3.

Certain of the OCRWM users of the CDB may be directly involved in facility design. For this reason the $C D B$ is now classified as quality affecting. All users will receive the CDB via OCRWM QA controlled distribution.

The CDB relies on the EIA (Energy Information Administration) for basic LWR spent fuel data and utilizes the ORIGEN2 code to calculate radiological properties. This peer review will qualify our specific usage of ELA data and ORIGEN2 in Revision 1. It is not intended to provide generic qualification for EIA data and ORIGEN2. Those programs are implementing their own QA plans which will, at some future date, provide generic QA qualification for ELA data and the ORIGEN2 code.

\section{BACKGROUND}

The original reports and data bases were prepared under QA standards existing at that time. An ORNL QA plan was prepared and followed. That plan stressed adequate documentation of data sources, archiving of key data source documents, and thorough documentation of the PC data bases via both user's guides and programmer's guides. It also required keeping a record of all persons who received the PC data bases. The hard-copy reports were given wide distribution by OSTI via "category" distribution (404 copies) plus a specific (by name) distribution of 230 copies. Subsequently, about 300 copies were distributed to various requestors.

Since the original report was issued, work has continued to upgrade, expand, and update the CDB, in preparation for the revision which is the subject of this peer review. This upgrading work is documented and has been (or will be) published as ORNL technical reports. The pertinent reports are listed in the References section and cover (a) a classification scheme for LWR assemblies. ${ }^{9}$ (b) descriptive data on GE BWR assemblies, ${ }^{10}$ (c) aspects of non-LWR spent fuels, ${ }^{11}$ and (d) sensitivity tests on ORIGEN2, the code used to calculate r diological properties. ${ }^{12}$

The above upgrading work, plus a 3-year update on inventories and various other improvements, have been (or will be) incorporated in Revision 1. Table 1 gives the overall contents of Revision 1 by volumes, chapters, and appendices. Volumes 1-4 were issued in draft form last July and are ready for peer review. Volumes 5-6 are in preparation and will be issued in draft form later this year. The numbering scheme for volumes, chapters, and appendices is described in Section 4.

In order to comply with current QA requirements, Revision 1 will undergo a formal peer review to qualify it for use by OCRWM and OCRWM contractors for the purposes stated earlier. After peer review has been completed and the draft report modified accordingly, the new volumes and their supporting PC data bases will be issued. It is planned to have open publication but to use controlled distribution to directly-involved OCRWM staff and OCRWM-contractor personnel. 


\section{Appendix A (continued)}

\section{PEER REVIEW PROCESS}

The peer review process is an acceptable procedure to qualify data which were not collected in conformance with an established (OCRWM-level) QA program. ${ }^{7}$ The purpose of this peer review is to establish the adequacy of the data reported in Rev. 1 of DOE/RW-0184. ${ }^{1}$ The first step in the peer review process is the preparation of a plan, which is fulfilled by this document. The plan must address these topics:

Organization of the peer review group, including a chairman, secretary, and technically-qualified peer review panels;

Identification of specialized technical areas and structure of the peer review paneis; Duties and qualifications of the peer review group chairman, secretary, and panel members;

Review criteria and methodology;

Submittal of comments and response;

Comment resolution meeting;

Preparation of the Peer Review final report: and

Schedule to be followed.

The peer review group will consist of a chairman, secretary, and peer reviewers, whose qualifications and duties are described in Section 5. Because of its technical scope, peer review of DOE/RW-0184, Rev. 1 will require several review panels, each consisting of three or more members. The rationale for this is given in Section 4.

The OCRWM Systems Integration Program manager, Oak Ridge National Laboratory, has been designated by OCRWM as peer review chairman. The peer review chairman has also been delegated responsibility, under section 4.0 of QAAP 3.3, to appoint members to the peer review panets. determine the scope of the peer review, establish peer reviewer qualifications, and assure that the peer review plan is prepared and carried out.

\section{TECHNICAL AREAS AND STRUCTURE OF REVIEW PANELS}

The draft Revision 1 report consists of six volumes that include five chapters and 17 appendices, as follows (note that the appendices are numbered to indicate the chapter they support):

Volume 1: Chapter 1, Summary

Chapter 2, LWR Spent Fuel

Chapter 3, Immobilized HLW

Appendix 1A, ORIGEN2 Overview

Appendix 1B, ORIGEN2 Library Data

Appendix 1C, ORIGEN2 Interpolation Functions

Volume 2 Appendix 2A: Physical Descriptions of LWR Fuel Assemblies

Volume 3 Appendices 2B, C, D, E:

LWR Assemblies Data User's Guide

LWR Radiological Data User's Guide

LWR Quantities Data User's Guide

LWR Serial Numbers Data User's Guide 
Volume 4 Appendices 3A, B, C:

ORIGEN2 Decay Tables for HLW

Interim HLW Forms

User's Guide to the HLW PC Data Base

Volume 5 Appendices $2 \mathrm{~F}$ and 2G:

Physical Descriptions of LWR Nonfuel Assembly Hardware

User's Guide to the LWR Nonfuel Assembly Data Base

Volume 6: $\quad$ Chapter 4. Non-LWR Spent Fuels

Chapter 5. Miscellaneous Wastes

Appendices 4A, B, C, D,

Nuclear Reactors at Educational Institutions In The United States

Supplemental Data for Fort St. Vrain Spent Fuel

Supplemental Data for Peach Bottom 1 Spent Fuel

Supplemental Data for FFTF Spent Fuel

There are seven broad technical areas represented in the above volumes (but not necessarily on a volume-by-volume basis). These are:

1. Summary (and Overall Content): Chapter 1

2. LWR Spent Fuel: Chapter 2 and Appendices $2 A, B, C, D, \&$ E

3. High-Level Waste: Chapter 3 and Appendices 3A, B, \& C

4. ORIGEN2: Appendices 1A, B, \& C

5. LWR Non-Fuel Assembly Hardware: Appendices $2 F$ \& G

6. Non-LWR Spent Fuel: Chapter 4 and Appendices 4A, B, C, \& D

7. Miscellaneous Wastes: Chapter 5

Thus, seven review panels will be required in order to adequately cover these seven specialized technical areas. The suggested organizational representation on these panels is given in Table 4. A check list showing which chapters and/or appendices each panel is responsible for is given in Table 5. In order to achieve the goal of determing technical competence and organizational comprehensiveness, the panel members shall be selected to represent a spectrum of DOE, contractor. and utility interests. Substitutions or additions of panel members may be made at the discretion of the peer review group chairman, with confirmation by the OCRWM Task manager.

\section{DUTIES AND QUALIFICATIONS}

Duties and qualifications are summarized in Table 6 for all of the Peer Review Group: the chairman. the secretary, and the panel members. Forms to be filled out by panel members verifying their independence and their technical qualifications are given as Tables 7 and 8 . In those cases where total independence cannot be met, a documented rationale as to why someone of equivalent technical qualifications and greater independence was not selected shall be included in the peer review report. 


\section{Appendix A (continued)}

These forms are to be completed and returned prior to commencement of the Peer Review.

The chairman and secretary are not required to be independent of the work being reviewed. In fact. the requirement that they be familiar with the work requires some direct prior involvement on their part. On the other hand, panel members must be independent, as defined in Table 6 . However, this does not preclude involvement in related work, or DOE funding via other activities. Because of the highly-specialized nature of some of the subject matter of this report, only people who work for (or have worked for) DOE or DOE prime contractors may have the necessary expertise to perform an adequate review of some sections.

The Peer Review checklist (Table 9) will be maintained by the Peer Review Chairman. As each action is completed, the Chairman will sign and date the form in the space to the left of each action. Upon completion of the Checklist, the Chairman will transmit it to the cognizant OCRWM Associate Director for approval.

\section{REVIEW CRITERIA AND METHODOLOGY}

The report is to be reviewed for its adequacy, in terms of accuracy, assumptions, calculations. extrapolations, interpretations, methodology, and references. In this instance, since the report is simply a data base, there are no conclusions as such to be critiqued. Because of the nature of this report, documentation of data sources is an especially important aspect of the peer review. Reviewers are to pay particular attention to the following:

Adequacy: Is enough information provided? Is it provided in a suitable format? Where explanations are needed, are they given?

Accuracy: Are the data and other information correct? Are they presented correctly?

References: Are the proper references provided? Are enough references provided? Have the references been cited correctly?

In addition, the following factors should also be considered:

Validity of basic assumptions and acceptance requirements employed;

Uncertainty of results, and consequences if incorrect;

Appropriateness and limitations of methodology and procedures;

Alternative interpretations; and

Verification of computer software.

The procedures to be used are as follows: Each reviewer will review those portions of the subject matter as delineated in Table 5 and as specifically instructed in each reviewer's copy of the Peer Review transmittal letter. The reviewers will use the comment form shown in Table 10 to document each comment. This comment form provides a uniform format which identifies the location in the text, gives the comment, and provides space for the author's response. Where it would be helpful, the reviewer may mark up the item in question on the draft report and submit a copy of that page. 
Wherever it is not unreasonable to do so, comments should be submitted one per page; this will facilitate all steps of the review process. Generic comments, which apply to more than one specitic location, can be made using the standard form, citing the multiple locations to which the same comment applies. Minor editorial comments (spelling, ubvious typos, etc.) are not an objective of this review but will, of course, be welcomed; these can simply be listed on a single piece (or pieces) of paper, or marked directly on the reviewer's copy and returned to the chairman. Reviewers may also use corroborating data or results of confirmatory testing (if acquired under a 10 CFR 60, subpart G QA program) for the purpose of establishing the qualification of the material subject to this Peer Review, should those techniques be appropriate.

The Chairman will arrange for copies of references or other documents, requested by individual reviewers, to be transmitted to those reviewers on an as-needed basis. The Chairman will assure that the materials transmitted are the correct revisions, editions, etc.

\section{COMMENTS AND RESPONSE}

The form for submittal of comments was described in the previous section. This form aiso has space for response by the authors. The comment forms will be sent to the chairman by the panel members. The chairman will review these, then give them to the authors for their response. Prior to the comment resolution meeting, the chairman will review the authors' response.

\section{COMMENT RESOLUTION MEETING AND PEER REVIEW REPORT}

The purpose of the comment resolution meeting is to allow discussion busween authors and reviewers and among the reviewers themselves. Such discussion stimulates additional comments and also allows authors and reviewers to achieve understanding on more complex questions. The peer review report will be issued by the chairman. This will be a concensus-type report, signed by all panel members. However, if there are any dissenting opinions these will be duly noted and explanations given with the minority views included in the report.

\section{SCHEDULE}

The desired schedule is given in Table 11. Changes can be made by the chairman, should this be necessary. The Appendix gives suggestions for panel members.

\section{REFERENCES}

1. Oak Ridge National Laboratory, "Characteristics of Potential Repository Wastes". DOE/RW0184, R1 (DRAFT); Volumes 1-4, July 1990; Volumes 5-6, to be issued.

2. OCRWM, Indoctrination and Training, QAAP 2.1, Rev. 1.

3. OCRWM, Verification of Personnel Qualifications, QAAP 2.2, Rev. 0.

4. OCRWM, Technical Document Review, Procedure No. QAAP 3.1., Rev. 0

5. OCRWM, Peer Review, QAAP 3.3, Rev. 0.

6. U.S. Nuclear Regulatory Commission, Peer Review for High-level Nuclear Waste Repositories, NUREG-1297, February 1988. 
7. U. S. Nuclear Regulatory Commission, Qualification of Existing Data for High-level Nuclear Waste Repositories, NUREG-1298, February 1988.

8. U.S. Department of Energy, Characteristics of Spent Fuel, High-Level Waste, and Other Radioactive Wastes Which May Require Long-term Isolation, DOE/RW-0184, Vols. 1-6, December 1987; Vols. 7-8, June 1988.

9. R.S. Moore, D.A. Williamson, and K.J. Notz, A Classification Scheme for LWR Fuel Assemblies, ORNL/TM-10901, Oak Ridge National Laboratory, November 1988.

10. R.S. Moore, and K.J. Notz, Physical Characteristics of GE BWR Fuel Assemblies, ORNL/TM-10902, Oak Ridge National Laboratory, June 1989.

11. R. Salmon, and K.J. Notz, Non-LWR and special LWR Spent Fuels: Characteristics and Criticality Aspects of Packaging and Disposal, ORNL/TM-11016, Oak Ridge National Laboratory, January 1990.

12. T.D. Welch, K.J. Notz, and R.J. Andermann, ORIGEN2 Sensitivity to Enrichment and Other Factors, ORNL/TM-11333, (In preparation). 
TABLE 1. ORGANIZATIONAL STRUCTURE OF DOE/RW-0184, REVISION 1

VOLUME 1

FOREWORD

PREFACE

ORDER FORM FOR PC DATA BASES

ACKNOWLEDGEMENTS

LIST OF ACRONYMS

1. SUMMARY

1.1 INTRODUCTION

1.2 LWR SPENT FUEL

1.3 HIGH-LEVEL WASTE

1.4 NON-LWR SPENT FUELS

1.5 MISCELLANEOUS WASTES

2. LWR SPENT FUEL

2.1 INTRODUCTION

2.2 ASSEMBLY DESCRIPTIONS

2.3 QUANTITIES OF INTACT SPENT FUEL

2.4 RADIOLOGICAL PROPERTIES OF INTACT SPENT FUEL

2.5 DEFECTIVE FUEL

2.6 SPECIAL LWR FUEL FORMS

2.7 SPENT FUEL DISASSEMBLY HARDWARE

2.8 NONFUEL ASSEMBLY HARDWARE

3. IMMOBILIZED HIGH-LEVEL WASTE

3.1 SUMMARY

3.2 WEST VALLEY DEMONSTRATION PROJECT FOR COMMERCIAL HLW

3.3 SAVANNAH RIVER SITE (SRS) DEFENSE HLW

3.4 HANFORD SITE (HANF) DEFENSE HLW

3.5 IDAHO NATIONAL ENGINEERING LABORATORY (INEL) DEFENSE HLW

APPENDIX 1A ORIGEN2 OVERVIEW

1B ORIGEN2 LIBRARY DATA

IC ORIGEN2 INTERPOLATION FUNCTIONS

DISTRIBUTION LIST 
TABLE 1. Continued

APPENDIX 2A

VOLUME 2

PHYSICAL DESCRIPTIONS OF LWR FUEL ASSEMBLIES

VOLUME 3

APPENDICES 2B, 2C, 2D, and 2E

USER'S GUIDE TO THE LWR ASSEMBLIES DATA BASE

USER'S GUIDE TO THE LWR RADIOLOGICAL DATA BASE

USER'S GUIDE TO THE LWR QUANTITIES DATA BASE

USER'S GUIDE TO THE SERIAL NUMBER DATA BASE

VOLUME 4

APPENDICES 3A, 3B, and 3C

ORIGEN2 DECAY TABLES FOR IMMOBILIZED HIGH-LEVEL WASTE

INTERIM HIGH-LEVEL WASTE FORMS

USER'S GUIDE TO THE HIGH-LEVEL WASTE PC DATA BASE

APPENDICES 2F AND 2G

VOLUME 5

PHYSICAL DESCRIPTIONS OF LWR NON-FUEL ASSEMBLY HARDWARE

USER'S GUIDE TO THE LWR NON-FUEL ASSEMBLY DATA BASE

\section{VOLUME 6}

4. NON-LWR SPENT FUEL

5. MISCELLANEOUS WASTES

APPENDICES 4A, 4B, 4C, AND 4D

NUCLEAR REACTORS AT EDUCATIONAL INSTITUTIONS

SUPPLEMENTAL DATA FOR FORT ST. VRAIN SPENT FUEL

SUPPLEMENTAL DATA FOR PEACH BOTTOM 1 SPENT FUEL

SUPPLEMENTAL. DATA FOR FFTF SPENT FUEL 
TABLE 2. Menu-driven PC Data Bases Supporting Characteristics Data Base (DOE/RW-0184. Rev. 1)

LWR Radiological Data Base - Contains radionuclide compositions. heat generation rates, curies, photon spectra, and other information as a function of spent fuel type (i.e. BWR or PWR), buinup. enrichment, and decay time.

LWR Assemblies Data Base - Contains detailed physical descriptions of fuel assemblies and radiological properties of spent fuel disassembly (SFD) hardware.

High-Level Waste Data Base - Contains physical. chemical, and radiological descriptions of high-level waste. both as the interim form and the immobilized form in canisters.

LWR NFA Hardware Data Base - Contains physical and radiological descriptions of nonfuel assembly hardware: i.e. nontuel-bearing hardware other than SFD hardware.

LWR Quantities Data Base - Contains data on discharged fuel. as historical inventories and as projected quantities. based on EIA data supplied to them by the utilties.

LWR Serial Numbers Data Base - Contains the serial numbers of individual fuel assemblies: easily cross-referenced to the Quanitities. Assemblies. and Radiological data bases. 
TABLE 3. Kinds of Data in the CDB

\author{
Physical Descriptions \\ Dimensions \\ Mass \\ Fabrication Data \\ Drawings \\ Chemical Compositions \\ Fuel or Waste Form per se \\ Structural Materials (alloys) of \\ Assemblies, Elements, or Canisters
Radiological Properties
Thermal Source Strength
Gamma Radiation
Neutron Source Strength
Individual Nuclides
Integral Heats \\ Inventories \\ Mass \\ Unit Count (Assemblies, elements. canisters) \\ LWR Assembly Serial Numbers \\ Projected Quantities \\ Mass \\ Unit Count
}


TABLE 4. Technical Review Panels (Suggested organizational representation)

1. Summary and Overall Panel

Number of

DOE/RW: System Engineering

Members

Transportation \& Logistics

MRS/storage

Geologic Disposal

2. LWR S zent Fuel Panel

EPRI (utility point-of-view) 5

EIA (RW-859 data)

PNL/MCC (ATMs)

LLNL (Waste Package)

PNL (Assemblies and SFD Hardware)

3. HLW Panel

West Valley

Savannah River

5

Hanford

Idaho Falls

IDB (all HLW)

4. ORIGEN2 Panel

DOE/RW

3

Edison Electric Institute

4

Johnson Associates. Inc.

5. Non-Fuel Assembly Hardware Panel

PNL

General Electric

Westinghouse

6. Non-LWR Spent Fuel Panel

Idaho Chemical Processing Plant

Savannah River

General Atomics

7. Miscellaneous Wastes Panel

EG\&G/IDAHO

PNL

$\mathrm{DGE} / \mathrm{NE}$ 


\section{Appendix A (continued)}

ঠण
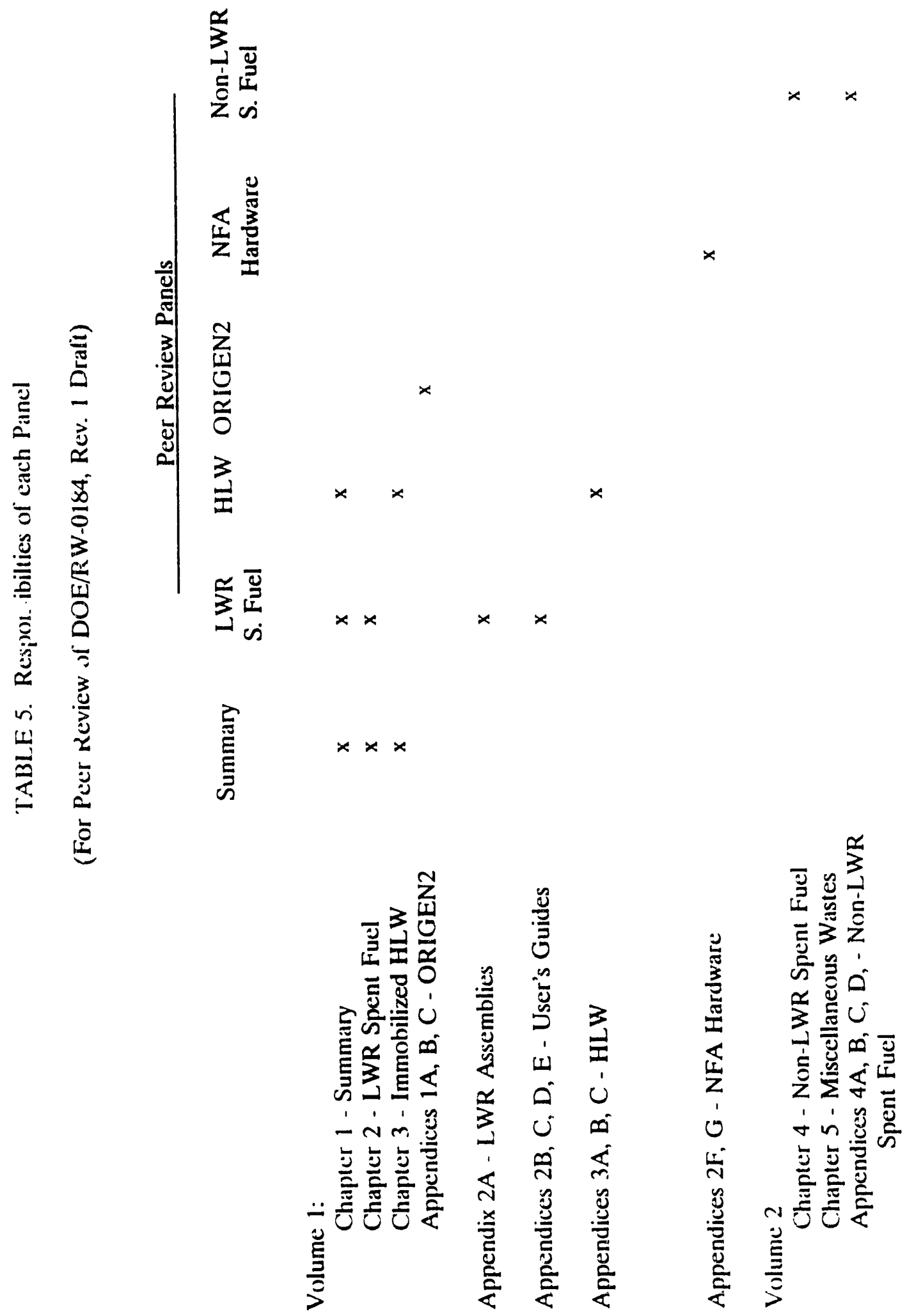


\section{Appendix A (continued)}

\section{TABLE 6. Duties and Qualifications of Peer Review Group}

\section{Chairman:}

\section{Duties}

1. Generally oversee that materials are provided, work is getting done. and schedule is followed;

2. Provide any procedures that may be required;

3. Provide any additional back-up data or reports that may be requested;

4. Act as the chairman of the close-out meeting, and resolve any differences:

5. Complete all actions required by the peer review checklist (see Table 9);

6. Establish Indoctrination and Training requirements.

\section{Qualifications}

1. Overall familiarity with the draft report and its intended utilization;

2. Substantial related technical background:

3. Appropriate formal education (B.S. or higher) pertinent to the technical areas;

4. Chairmanship abilities;

5. Prior experience as a peer review committee member is desirable, but not essential;

6. Certification per QAAP 2.2;

7. Indoctrination and Training per QAAP 2.1. 
Secretary:

\section{Duties}

1. Keep records of panel members' qualifications and independence certifications;

2. Keep records of reviewers' comments, the authors' responses, and final resolutions:

3. Provide any forms or QA documents that may be required;

4. Prepare the draft and final versions of the peer review report;

5. Do the above in keeping with $\mathrm{QA}$ requirements.

\section{Qualifications}

1. Familiarity with QA procedures and requirements;

2. Appropriate training and experience with QA work (at least two years);

3. General familiarity with the technical task;

4. Access to clerical assistance;

5. Prior experience with peer review functions is desirable, but not essential.

6. Certification per QAAP 2.2;

7. Indoctrination and Training per QAAP 2.1. 


\section{$\underline{\text { Panel Members }}$}

\section{Duties}

1. Review the draft report against the criteria described in Section 6 of this plan:

2. Submit written comments of the above review, in particular for their area of specialization, but with the option of also commenting on other areas;

3. Attend and participate in the close-out meeting, to be held in Oak Ridge;

4. Review the draft review summary and either concur or provide a written minority position;

5. Sign the final version of the peer review report.

\section{Qualifications}

1. Independence from the work being reviewed. This means that the panel member was not directly involved in the work as a participant, supervisor, or consultant and that his or her primary funding is not dependent on this review;

2. Time available during the scheduled period to perform the review;

3. Availability to attend their 1-day review close-out session in Oak Ridge; panel members are free to sit-in on the other review sessions if they desire;

4. Certification per QAAP 2.2;

5. Indoctrination and Training per QAAP 2.1;

6. Detailed technical knowledge and experience in their area of specialization, including the related technical literature. This should be an appropriate combination of educational background, prior and current work experience, and evidence of direct personal activity in the area of specialization e.g., by authoriship of technical reports and/or journal articles. presentation of papers at technical symposia, or participation in pertinent technical meetings, such that the panel member would be technically capable of having written the section under review assuming, of course, that suitable resources were made available. 
TABLE 7 Certification of Independence

(Required of all Panel Members)

Name:

Affiliation:

Panel:

This is to certify that I am independent of the preparation of DOE/RW-0184, Rev. 1. I was not involved in its preparation as either a participant, supervisor, or consultant. My funding is not connected to this report nor dependent on this review. I have also read the Peer Review Plan and concur with it.

Signed Date

NOTE: Because of the highly specialized technical nature of this report, a panel member may have been involved in providing certain data to $C D B$ staff. If so this uniquely qualifies that person as a reviewer of those data. Where this is not the case, certify to that fact:

Signed Date

Where this is the case, identify the data involved and so certify:

Nature of data provided: 
TABLE 8. Certification of Technical Qualification and Indoctrination and Training

(Required of Chairman, Secretary, and all Panel Members)

Name:

Affiliation:

Address:

Phone No.:

\section{TECHNICAL OUALIFICATIONS}

Education (degrees obtained, when and where obtained; areas of specialization; special training courses):

Work Experience (brief summary, citing facts pertinent to this peer review):

\section{INDOCTRINATION AND TRAINING}

I have read and understand the following materials:

a) Peer Review Plan for DOE/RW-0184, Rev. 1

b) QAAP 3.3 "Peer Review"

$$
\text { Signed }
$$

Date

\section{VERIFICATION}

I hereby verify that the individual named above has the stated qualifications, and has completed the required Indoctrination and Training exercise.

Signed

Date 
TABLE 9

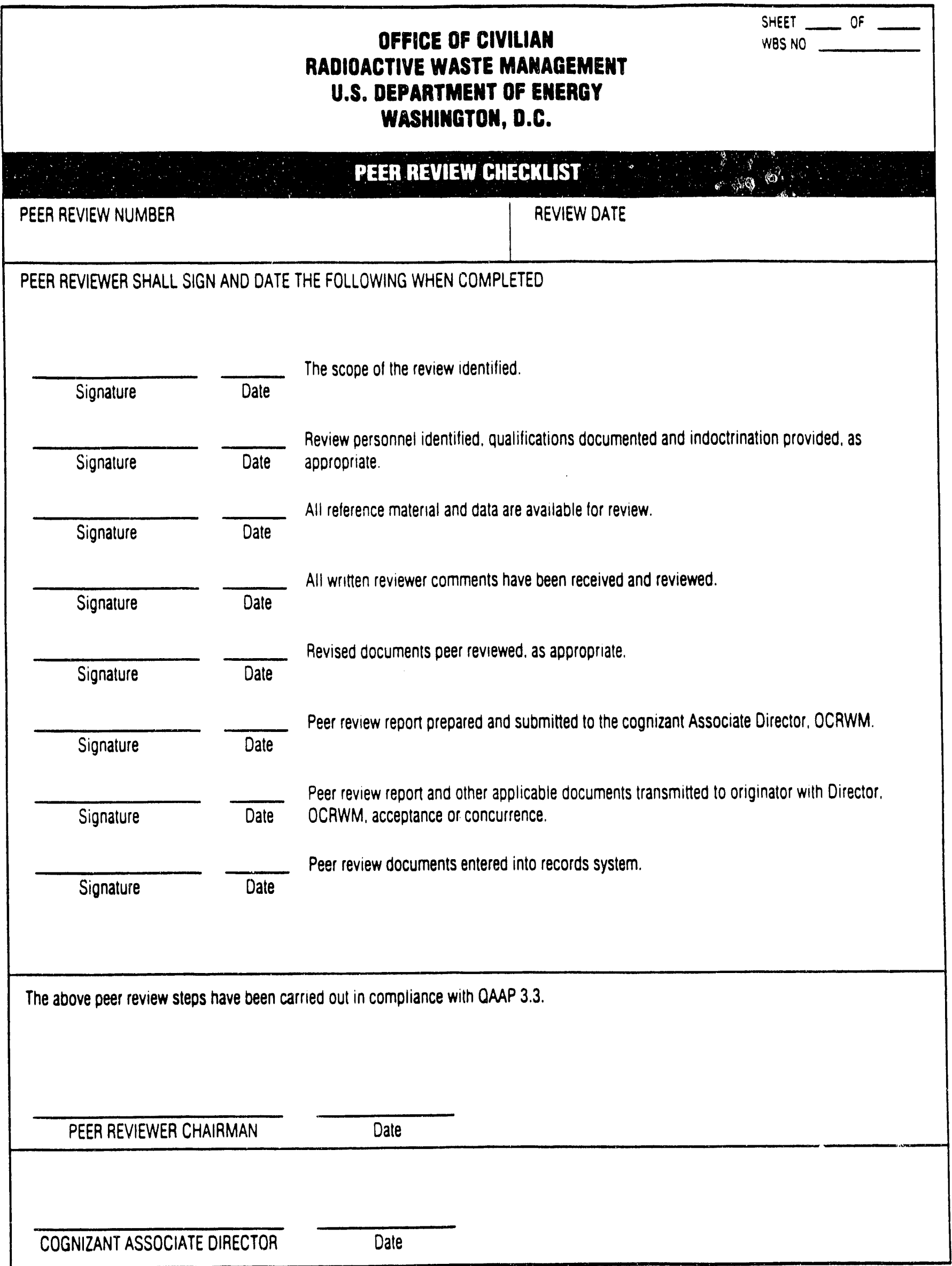


TABLE 10. Comment Form

(To be submitted by Review Panel members; one comment per page.)

Commentor (initials):

Location (page, paragraph, line):

Comment:

Response by authors:

Final resolution: 
TABLE 11. Suggested Schedule for Peer Review For All Six Volumes

1. Prepare Peer Review Plan

Feb. 1, 1991

2. Obtain acceptance of Plan from DOE/HQ

Feb. 15

3. Issue final report of peer review

Aug. 30

For Volumes $1,2,3$, and 4

1. Confirm reviewers

Feb. 28

2. Mail draft report to reviewers

March 1

3. Receive written comments

April 1.

4. Respond to comments

April 26

5. Comment resolution meeting (in Oak Ridge)

May $8,9,10$

6. Send out draft of review summary

May 31

7. Receive final responses

June 17

\section{For Volumes 5 and 6}

1. Confirm reviewers

April 1, 1991

2. Mail draft report to reviewers

April 15

3. Receive written comments

June 3

4. Respond to comments

June 28

5. Comment resolution meeting (in Oak Ridge)

July 11,12

6. Send out draft of review summary

July 26

7. Receive final responses

Aug 16 
Appendix: Technical Review Panels

(Suggested Individual Members)

Volumes $1,2,3,4$

1. Summary and Overall Panel

System Engineering

Transportation \& Logistics

MRS/storage

Geologic Disposal

2. LWR Spent Fuel Panel

EPRI (utility point-of-view)

EIA (RW-859 data)

PNL/MCC (ATMs)

LLNL (Waste Package)

PNL (SFD Hardware)

3. HLW Panel

West Valley

Savannah River

Hanford

Idaho Falls

IDB (all HLW)

4. ORIGEN2 Panel

DOE/RW

Edison Electric Institute

Johnson Associates, Inc.

Volumes 5 and 6

5. Non-Fuel Assembly Hardware Panel

General Electric

Westinghouse

PNL 
Appendix A (continued)

6. Non-LWR Spent Fuel Panel

Idaho Chemical Processing Plant

Savannah River

General Atomics

7. Miscellaneous Wastes Panel

EG\&G/IDAHO

PNL

$\mathrm{DOE} / \mathrm{NE}$ 
Appendix B

\section{CHEONOLOGICAL SUMMARY OF SIGNIFICANT PEER REVIEW PROCESS EVENTS}

March 20 - 23, 1990

March 28, 1990

May 3, 1990

June 7, 1990

June 29, 1990

October 15, 1990

December 14, 1990

December 21, 1990

February 8, 1991

February 20, 1991

March 7, 1991

March 19, 1991

March 22, 1991

April 8, 1991
OCRWM HQ Office of Quality Assurance (OQA) conducted a surveillance of the development of Office of Systems Integration and Regulations (OSIR) documents DOE/RW-0125, DOE/RW-136, and DOE/RW-0184. Deficiencies were identified.

OSIR issued Deficiency Report responses to OQA.

OSIR resubmitted Deficiency Report responses to OQA.

Approved Surveillance Report OCRWM-HQ-SR-90-001 issued by OQA, including Deficiency Report DR-90-018.

In response to the June 7 surveillance report, OSIR issued a Deficiency Report response to OQA.

Revised Deficiency Report response issued to OQA by the Office of Systems and Compliance (OSC). DOE re-organization created OSC and assigned it responsibility for completion of the DR-90-018 remedial actions. The revised response established a due date of September 30, 1991 for completion of the Deficiency Report remedial actions.

Peer review chairman submitted the Peer Review Plan to OSC for review and acceptance.

OCRWM issued the FY 1991 Programmatic Funding and Guidance memorandum which included direction for ORNL to conduct the peer review.

Peer review chairman issued a letter to OSC identifying potential peer reviewers by panel.

OSC issued a letter accepting the Peer Review Plan.

Peer review chairman began issuing peer reviewer appointment letters.

Peer review chairman issued a letter to OSC requesting that a QA surveillance be scheduled.

Peer reviewer certification forms began to arrive at ORNL.

First High Level Waste Panel comments received. 


\section{Appendix B (continued)}

April 15, 1991

April 25, 1991

May 21, 1991

June 3, 1991

June 11, 1991

June 17, 1991

July $18-19,1991$

July 24, 1991

July 29, 1991

September 4, 1991

September 18, 1991

September 19, 1991

September 27, 1991

December 16, 1991

December 16, 1991

December 30, 1991

January 3, 1992

January 22, 1992

January 24, 1992

February $24-26,1992$
First LWR Spent Fuel Panel comments received.

First ORIGEN2 Panel comments received.

First Summary and Overall Panel comments received.

Letter issued from ORNL to OSC requesting postponement of the QA surveillance due to the death of the peer review chairman.

All peer reviewers were contacted to concur in the appointment of a new peer review chairman.

OSC issued a letter recognizing the new peer review chairman.

OQA conducted a surveillance of the peer review process.

ORIGEN2 panel comment resolution meeting conducted at ORNL.

Peer review chairman issued a letter to OSC advising of a slip in peer review completion date to December 31, 1991.

First Non-LWR Spent Fuel Panel comments received.

All High Level Waste Panel comments resolved.

OSC issued a letter to OQA extending the due date for completion of DR-90-018 remedial actions to January 31, 1992.

First Miscellaneous Wastes Panel comments received.

Peer review chairman issued a letter to OSC advising of a slip in peer review completion date to February 28, 1992.

All Miscellaneous Wastes Panel comments resolved.

All Non-LWR Spent Fuel Panel comments resolved.

OSC issued a letter to OQA extending the due date for completion of DR-90-018 remedial actions to May 29, 1992.

First NFA Hardware Panel comments received.

All Summary and Overall Panel comments resolved.

OQA conducted an audit of the Systems Integration Quality Assurance program which included the peer review process. 


\section{Appendix B (continued)}

March 6, 1992

March 9, 19:,

April 10, 1992

May 6, 1992

July 8, 1992

July 8, 1992

September 8, 1992

October 5, 1992
All ORIGEN2 Panel comments resolved.

All LWR Spent Fuel Panel comments resolved.

Corrected volumes of Rev. 1, appropriate to each panel member, were transmitted for review by the panels.

The draft Peer Review Report (except for the NFA Hardware conclusions section) was transmitted to the panel members for review and approval. The NFA Hardware conclusions will be sent to the three panel members after that panel's comments are finalized.

All NFA Hardware Panel comments resolved.

NFA Hardware conclusions section of the draft Peer Review Report was sent to the three panel members for review and approval.

Comment incorporation verification completed for all panels.

All Peer Review Report approval pages received. 
Appendix C

\section{QUALTTY ASSURANCE RECORDS CATEGORIES}

The following categories of peer review documentation will be turned over to OCRWM for inclusion in the OCRWM QA records system.

- Qualification and Certification Forms

- Correspondence - includes correspondence between ORNL and the peer reviewers, and between ORNL and OCRWM

- Peer Review Plan

- Peer Review Checklist

- Comment Forms

- Panel Close-out Meeting Attendance Sheets

- Peer Review Report 


\section{Appendix D}

\section{RECOMMENDATIONS FOR FUTURE CDB EDITIONS}

1. M.J. Plodinec (MJP-001) recommended that the projections should be made to the year 2025 to be consistent with the Waste Acceptance Preliminary Specifications. This is applicable to the scoping statement made in Volume 1, page 1.3-1, paragraph 1.3.1, subparagraph 2 wherein projections are limited to the year 2020 by sponsor direction.

2. D. Andress makes the following recommendations:

- (DA-012) "future research into a discontinuity revealed when comparing plots (based on ORIGEN code produced data) of thermal power versus burnup at constant age and standard enrichment between PWRs and BWRs. Discontinuities were also noted in plots of neutron data."

- (DA-013) "research into the interpolation functions used in the data base system" and suggested that "additional and/or simplified interpolation functions should be done with the participation of the user community."

3. N.B. McLeod (NBM-008) suggests the possibility of adding direct fission yields for the fission products.

4. N.B. McLeod (letter dated 08/04/92) recommends that: "Strong consideration should be given to basing the 'standard' enrichment-burnup relationship in Appendix 1C on a firstorder (linear) relationship."

5. N.B. McLeod (letter dated 08/04/92) recommends that: "Additional measures should be considered to reduce the discontinuities occurring at the point of transition between the two different cross-section sets. The size of the discontinuities should be decreased by assuring that the two burnup-enrichment pairs used to generate the cross-sections are each on the 'standard' burnup-enrichment line, mentioned above. Consideration might also be given to using specific cross-sections at intermediate points by use of linear interpolation between the two points at which detailed cross-sections were developed."

6. M.L. Smith made a number of recommendations as follows:

- (letter dated 04/24/91) "To minimize requirements for a large number of DOE contractors having to independently develop limiting radiological characteristics for each fuel type, I suggest that future versions of the database include both best estimate and limiting radiological characteristics as a function of enrichment and burnup. This could be combined with the quantities database to determine overall totals and to determine the characteristics of the limiting fuel assemblies." 


\section{Appendix D (continued)}

- (letter dated $07 / 18 / 91$ ) "My comments on uncertainty and/or conservatisms can be resolved by noting in the section on future work that a study of uncertainties of the radiological characteristics should be considered. As indicated in one comment, I believe that the question of whether there is really any difference between Westinghouse 15X15 'Standard' and 'LOPAR' fuel needs to be resolved."

- (MLS-001) "Some statement of how to determine this axial variation is needed or a future version of the database should include limiting axial profiles for fuel assemblies."

- (MLS-011) "The ability to interpolate radiological characteristics as a function of enrichment and burnup allow for some evaluations of the variability in these characteristics. However, I believe that some additional study of the effect of burnable poisons, operating temperature, and core loading patterns is warranted."

- (MLS-020) "before the radiological characteristics database can be used for OCRWM systems design, or licensing analysis, more extensive studies will be required to establish limiting radiological parameters."

- (MLS-021) "Some experimental verification for ORIGEN2 would be useful, and needed."

- (MLS-022) "need to study other cycle variations"

7. C.L. Kerrigan raised an issue (CLK-004) which, although not a part of this peer review, must be addressed for qualification and future maintenance of the complete CDB system in quality-affecting work: "However, I feel that an issue remains on the qualification of the software used to operate (execute) the Characteristics Data Base. Since the software documentation (programmer's manuals, etc) was not reviewed during this peer review, it is difficult to make an assessment of the software system itself." 


\section{Appendix E}

\section{LESSONS LEARNED FOR FUTURE OCRWM PEER REVIEWS}

1. Instructions to reviewers should contain a recommendation that reviewers not only comment on a perceived error but provide a proposed change as part of the comment whenever possible.

2. A written set of instructions on the movement of original comments forms should be prepared at the beginning of the process. The addition of a flow sheet would also help.

3. The comment forms should also contain a specific place at the bottom of the form for the reviewer to indicate acceptance of the comment resolution.

4. Reviewers should be given an instruction to give all comments in either typed form or handwritten in black ink. The use of pencil or colored ink must be specifically excluded.

5. Instructions to reviewers should clearly state that continuing comments on the back of the comment forms is not an acceptable practice. Reviewers should be instructed to use continuation sheets when additional space is needed.

6. Instructions to reviewers and authors should state that white out (liquid paper) is not to be used for correction of comments. If a comment must be changed, either re-write it on a new form or strike out the words to be changed with black ink and insert the correct text.

7. All correspondence, review materials, etc. should be consistently sent out through a single distribution point - ideally the chairman. For example, when another organization (internal or contractor) is delegated responsibility to prepare materials for distribution, assure that they are actually transmitted through the single point and are not released through a secondary source.

8. As part of the Peer Review Plan, include the requirement to obtain a current, pertinent resume from each reviewer.

9. A formal peer review consumes a tremendous amount of time and effort on the part of both the peer review group and those responsible for the body of work reviewed.

10. Estimating the time required to complete the review process is very uncertain. Since the peers must be technically capable of reviewing the subject matter and must be independent (to the extent required) of the material being reviewed, their participation is often obtained as an uncompensated service. Therefore, the peer review chairman has little leverage in holding peers to a schedule and must depend upon their willingness to cooperate and compete with other demands on their time. 


\section{Appendix F}

\section{QUALIFICATIONS OF PEER REVIEWERS}

(Full documentation of peer reviewer technical qualifications and evidence of independence is preserved in the $Q A$ records package as indicated in Appendix $C$ )

F. Michael Coony is qualified to serve as a peer reviewer on the High Level Waste Panel because he has a B.S. in Chemical Engineering and a M.S. in Environmental Engineering, and is affiliated with the Westinghouse Hanford Company with responsibility for preparing the High Level Waste input to the Integrated Data Base (IDB) and coordinating Hanford site inputs to the IDB.

Hershel W. Godbee is qualified to serve as a peer reviewer on the High Level Waste Panel because he has both a Bachelor and Doctorate in Chemical Engineering with specialization in heat and mass transport, and radioactive waste management. He is affiliated with the Oak Ridge National Laboratory and has been involved with radioactive waste management for over thirty years and responsible for the high-level waste chapter of the IDB for ten years.

C. Lee Bendixsen is qualified to serve as a peer reviewer on both the High Level Waste and the Non-LWR Spent Fuel Panels because he has a both a B.S. and M.S. in Chemical Engineering, and is affiliated with the Westinghouse Idaho Nuclear Company with responsibilities in chemical process design of uranium recovery from spent, high-enriched nuclear fuels, and management and minimization of related nuclear wastes. He is also involved in Uranium and Plutonium recovery and waste management for the proposed New Production Reactor ( 2 types) at the Idaho National Engineering Laboratory.

Ronald A. Palmer is qualified to serve as a peer reviewer on the High Level Waste Panel because he has a B.S. in Glass Science and both a M.S. and Ph.D. in Materials Science, and is affiliated with the West Valley Nuclear Services Company with responsibilities as principal engineer for vitrification process development.

M. John Plodinec is qualified to serve as a peer reviewer on the High Level Waste Panel because he has a B.A. in chemistry and Ph.D. in Physical Chemistry, and is affiliated with the Westinghouse Savannah River Company with sixteen years experience in projects relating to immobilization of high-level waste. The last ten years have been as supervisor of all HLW characterization studies at the Savannah River site.

Robert A. Watrous is qualified to serve as a peer reviewer on the High Level Waste Panel because he has a B.S. in Chemical Engineering with specialization in solvent extraction, and is affiliated with the Westinghouse Hanford Company. During the last four years on the Hanford vitrification project staff, he has been responsible for projections of glass canister production and canister activity. 


\section{Appendix F (continued)}

Billy M. Cole is qualified to serve as a peer reviewer on the LWR Spent Fuel Panel because he has twenty eight years of nuclear experience, and is affiliated with E.R. Johnson Associates, Inc. Mr. Cole has been a project manager for spent fuel storage requirements analysis, a member of the IDB Steering Committee, author of pre-RW-859 reactor data collection instruments for DOE, program manager for reactor data collection and dissemination activities at Pacific Northwest Laboratories (PNL), and a consultant to PNL and DOE on reactor data collection and end use requirements (RW859).

Ray W. Lambert is qualified to serve as a peer reviewer on the LWR Spent Fuel Panel because he has a B.S. in Chemical Engineering and Nuclear Engineering, and an MBA, and is affiliated with the Electric Power Research Institute (EPRI). Mr. Lambert is a technical specialist and project manager in the High-Level Waste \& Spent Fuel Program, Nuclear Power Division at EPRI and is responsible for research and development activities relating to spent fuel storage and transportation.

Herman R. Leider is qualified to serve as a peer reviewer on the LWR Spent Fuel Panel because he has a B.S. in Chemistry and a Ph.D., and is affiliated with Lawrence Livermore National Laboratory (LLNL). Mr. Leider is a task leader of fuel dissolution for the Yucca Mountain Project at LLNL.

Andy T. Luksic is qualified to scrve as a peer reviewer on both the LWR Spent Fuel and Non-Fuel Assembly Hardware Panels because he has a B.S. in Mathematics and a M.S. in Nuclear Engineering, and is affiliated with Pacific Northwest Laboratory. Mr. Luksic has spent his career in the nuclear engineering field including radiation shielding, neutronics calculations, and neutron activation analysis. Since 1983, he has worked extensively on OCRWM programs dealing with activated metals and their effects on the Civilian Radioactive Waste Management System (CRWMS).

John E. Mendel is qualified to serve as a peer reviewer on the LWR Spent Fuel Panel because he has a B.S. in Chemistry, and was affiliated with Pacific Northwest Laboratory (PNL) until his retirement in 1991. He spent ten years at PNL's Materials Characterization Center managing procurement and characterization of spent fuel Approved Testing Materials (ATMs). He previously worked ten years in development of the borcsilicate glass waste form, and over fifteen years in process assistance to the Redox and Purex separations plants.

David Andress is qualified to serve as a peer reviewer on the ORIGEN2 Panel because he has both a B.S. and M.S. in Mathematics, and is an independent consultant to government and industry. Mr. Andress has over 13 years experience with nuclear energy, has developed a number of models used by DOE for analyzing and forecasting nuclear industry trends and simulating the characteristics of wastes entering the CRWMS, including the Waste Stream Analysis model (which uses ORIGEN radiological data), the International Nuclear model, DISAG, and SNAPPS. He also has extensive experience with nuclear waste issues, models, and data.

N. Barrie McLeod is qualified to serve as a peer reviewer on the ORIGEN2 Panel because he has a B.A.Sc in Engineering Physics, and both a M.S.E and Ph.D. in Nuclear Engineering. Mr. McLeod is affiliated with E.R. Johnson Associates, Inc., has worked in the nuclear fuel area for the past thirty years, and was a joint developer of the Waste Stream Analysis computer model which extensively uses ORIGEN-based radiological data from the Characteristics Data Base (CDB). 


\section{Appendix F (continued)}

Marvin L Smith is qualified to serve as a peer reviewer on the ORIGEN2 Panel because he has a B.S. in Physics, Mathematics and a M.S. in Nuclear Engineering, and is affiliated with Virginia Power. $\mathrm{Mr}$. Smith is responsible for engineering on spent fuel projects, low-level radwaste processing systems, ALARA and radiation protection analysis.

James $\mathrm{L}$. Wheeler is qualified to serve as a peer reviewer on the Non-Fuel Assembly Hardware Panel because of his fifteen years of nuclear experience. Mr. Wheeler is a private consultant with experience in nuclear power plant operations and radioactive waste programs, as well as previous Nuclear Navy assignments.

Michael J. White is qualified to serve as a peer reviewer on the Non-Fuel Assembly Hardware Panel because he has a B.S. in Occupational Education and a M.E. in Nuclear Engineering, and is affiliated with E.R. Johnson Associates, Inc. Mr. White has over fifteen years experience in the nuclear industry including the Navy Nuclear Power School. He has supervised development and implementation of the Work Completion and Tracking Data Base for Nine Mile Point - Unit 2 and participated in the preparation of several reports and studies on the processing and storage of high level wastes which included the use of the HLW database.

N. Douglas Rickard is qualified to serve as a peer reviewer on the Non-LWR Spent Fuel Panel because he has a B.S. in Engineering Mechanics and a M.S. in Structural Mechanics, and is affiliated with General Atomics which designed high temperature, gas-cooled reactors. Mr. Rickard is responsible for managing the Nuclear Waste Management technical staff with projects including the design, fabrication and testing of two spent-fuel shipping casks and the DHLW shipping cask. Other projects include fuel-pool cleanup and nuclear-waste consolidation projects at Vermont Yankee and Niagara Mohawk Power corporations.

Matthew J. Beckum is qualified to serve as a peer reviewer on the Non-LWR Spent Fuel Panel because he has a B.S. in Mechanical Engineering and is affiliated with the Westinghouse Savannah River Company with responsibility for various types of spent fuel in the areas of fuel storage management, process scheduling, fuel classification, and fuel packaging reports.

Ray L. Pearson is qualified to serve as a peer reviewer on the Non-LWR Spent Fuel Panel because he has a B.S. in Chemistry and Mathematics, a M.S. in Physical Chemistry and Physics, and a Ph.D. in Metallurgy and Physical Chemistry, and is affiliated with Oak Ridge National Laboratory. Mr. Pearson has been a member of the IDB team since 1985 with responsibilities in the areas of TRU Wastes, Environmental Restoration Wastes, and Miscellaneous Radioactive Materials.

Meraj Rahimi is qualified to serve as a peer reviewer on the Miscellaneous Wastes Panel because he has a B.S. and M.S. in Nuclear Engineering, and is affiliated with Jacobs Engineering which provides technical support to OCRWM in managing the design, certification, and operation of casks for transporting spent-nuclear fuel. Mr. Rahimi has more than five years experience in nuclear waste management including development of transportation systems and performing total life cycle economic analysis for the CRWMS. 
Appendix F (continued)

Mary T. Magleby is qualified to serve as a peer reviewer on the Miscellaneous Wastes Panel because she has both a B.S. and a M.S. in Civil Engineering, and is affiliated with EG\&G Idaho, Inc. Ms. Magleby has responsibilities as technical leader for the Greater-Than-Class C Low-Level Radioactive Waste (GTCC LLW) Program, and provided technical management for preparation of the "GTCC LLW Characterization: Estimated Volumes, Raionuclide Activities, and Other Characteristics" report.

Roger R. Piscitella is qualified to serve as a peer reviewer on the Miscellaneous Wastes Panel because he has a B.S. and a M.S. in Mechanical Engineering, and a M.S. in Waste Management, and is affiliated with EG\&G Idaho, Inc. Mr. Piscitella has twenty three years experience in the nuclear industry with current responsibility for GTCC LLW characterization in EG\&G's National Low-Level Waste Management Program.

Robert G. Eoile is qualified to serve as a peer reviewer on the Summary and Overall Panel because he has a B.S. in Engineering Science, and is affiliated with Duke Engineering \& Services, Inc. with responsibilities as supervisor of the Monitored Retrievable Storage (MRS) Facility design group. Mr. Eble's exprience also includes nuclear group workleader, criticality and general nuclear analysis, spent fuel shielding analysis and design, reactor cavity streaming analysis and shield design, and spent fuel pool rerack criticality analysis.

Diane J. Harrison-Giesler is qualified to serve as a peer reviewer on the Summary and Overall Panel because she has a B.S. in Chemical Engineering and a A.S. in Mathematics, and is affiliated with the Department of Energy, Yucca Mountain Project Office. Ms. Harrison-Giesler is responsible for directing, administering and reviewing the technical and programmatic activities necessary for developing a waste package that is compatible with a repository site proposed for Yucca Mountain. She also has experience performing shielding calculations and isotopic analysis of waste and spent fuel for handling and shipping operations.

Camille L Kerrigan is qualified to serve as a peer reviewer on the Summary and Overall Panel because she has a B.S. and a M.A. in Mathematics, and is affiliated with TRW Environmental Safety Systems - the Management and Operating (M\&O) contractor for OCRWM. Ms. Kerrigan is responsible for managing the design and implementation of an M\&O technical data system to support DOE's Civilian Radioactive Waste Management System (CRWMS). She is also responsible for software verification and validation, and configuration management.

Ivan J. Sacks is qualified to serve as a peer reviewer on the Summary and Overall Panel because he has B.S., M.S. and Ph.D. degrees in Electrical Engineering, and is affiliated with R\&D Associates a subcontractor to TRW Environmental Safety Systems. Mr. Sacks is manager of the systems modeling task for the CRWMS M\&O contract, and is familiar with radioactive waste databases and CRWMS modeling needs. He also led teams that developed automated techniques for assessing the vulnerability of the safeguards (security) system of nuclear fuel cycle facilities while at Lawrence Livermore National Laboratory.

Helmut A. Worle is qualified to serve as a peer reviewer on the Summary and Overall Panel because he has a B.S. in Physics and a M.S. in Nuclear Physics, and is affiliated with EG\&G Idaho, Inc. Mr. Worle's responsibilities are currently in the cask systems development program. He provides technical support in the areas of nuclear and radiation safety, spent fuel assembly characteristics, and facility interface capabilities. 


\section{DISTRIBUTION}

\section{INTERNAL DISTRIBUTION}

1. J. M. Begovich

2. A. G. Croff

3. R. K. Genung

4. H. W. Godbee

5. K. H. King-Jones

6. S. B. Ludwig

7. A. P. Malinauskas

8. K. J. Notz

9. R. M. Pearson
10. R. B. Pope

11. W. J. Reich

12. A. A. Richmond

13. R. Salmon

14. T. D. Welch

15. Central Research Library

16. Laboratory Records Department

17. Laboratory Records, ORNL RC

18. ORNL Y-12 Tech. Library, Doc.

Ref.Sec.

19. ORNL Patent Section

\section{EXTERNAL DISTRIBUTION}

20. DOE - Office of Civilian Radioactive Waste Management, 1000 Independence Ave., Washington, D. C. 20585

R. W. Slark

W. A. Lemeshewsky

T. D. Nguyen

21. DOE - Yucca Mountain Project Office, P. O. Box 98608, Las Vegas, NV 89193-8608

D. J. Harrison

22. DOE - Oak Ridge Field Office, P. O. Box 2008, Oak Ridge, TN 37831

R. N. Collier

23. Lawrence Livermore National Laboratory, P. O. Box 808, Livermore, CA 94550

H. R. Leider

24. Pacific Northwest Laboratory, P. O. Box 999, Richland, WA 99352

A. T. Luksic

25. Westinghouse/Hanford Company, P. O. Box 1970, Richland, WA 99352

F. M. Coony

R. A. Watrous 
26. Westinghouse/Idaho Nuclear Company, P. O. Box 4000, MS 5213, Idaho Falls, ID 83403 C. L. Bendixsen

27. Westinghouse/Savannah River Company, Bldg. 244-2H, P. O. Box 616, Aiken, SC 29801-0001

$$
\begin{aligned}
& \text { M. J. Beckum } \\
& \text { M. J. Plodinec }
\end{aligned}
$$

28. Automated Sciences Group, 800 Oak Ridge Turnpike, Suite C-102, Oak Ridge, TN 37830
C. G. Cowart
R. S. Moore

29. CER Corporation, 2500 Wilson Blvd., Suite 202, Arlington, VA 22201

R. D. Brown

30. David Andress Associates, Inc., 11008 Harriet Lane, Kensington, MD 20895
D. Andress

31. Duke Engineering and Services, Inc., MRS Design Group, P. O. Box 1004, Charlotte, NC 28202-1004

R. G. Eble

32. EG\&G Idaho, P. O. Box 1625, Idaho Falls, ID 93415-1540
M. T. Magleby
R. R. Piscitella
H. A. Worle

33. Electric Power Research Institute, 3412 Hillview Avenue, Palo Alto, CA 94304

R. W. Lambert

34. E. R. Johnson Associates, Inc.,9302 Lee Highway, ICF Bldg. 2, Suite 700, Fairfax, VA 22031
B. M. Cole
N. B. McLeod
M. J. White

35. Jacobs Engineering Group, Inc., 955 L'Enfant Plaza, S.W., Washington, DC 20024

M. Rahimi 
36. General Atomics, P. O. Box 85608, 15-220, San Diego, CA 92186-9784

N. D. Rickard

37. John E. Mendel, 2510 W. Crown, Spokane, WA 99205

38. Marvin L. Smith, 5707 Hillview Drive, Mechanicsville, VA 23111

39. TRW, Environmental Safety Systems, 2650 Park Tower Drive, Suite 800, Vienna, VA 22180-7306

\section{J. Sacks}

40. TRW, Environmental Safety Systems, Inc., 2650 Park Tower Drive, Suite 800, Vienna, VA 22180-7306

Camille L. Kerrigan

41. West Valley Nuclear Fuel Services Co., P. O. Box 191, West Valley, NY 14171-0191

$$
\text { R. A. Palmer }
$$

42. James L. Wheeler, 132 Tillinghast Road, Danielson, CT 06239

43-44. OSTI, P. O. Box 62, Oak Ridge, TN. 37831

45. Office of Assistant Manager for Energy Research and Development, U.S. Department of Energy, Oak Ridge Field Office, P. O. Box 2001, Oak Ridge, TN 37831-8600 

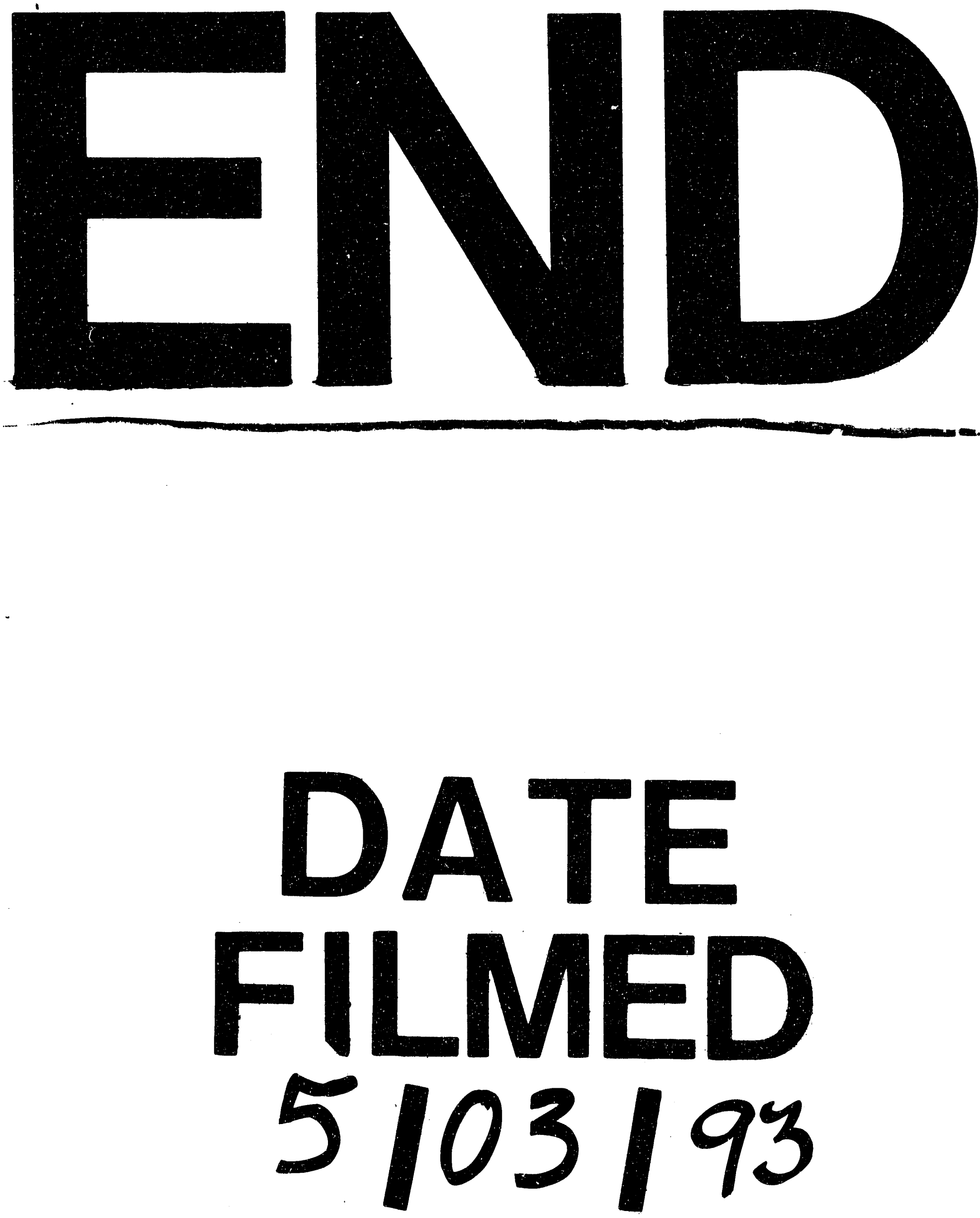
1 